\title{
Fatos, valores e o mundo-da-vida: argumentos epistemológicos para avaliação no âmbito da gestão social
}

\author{
VALDerí de CAStro AlCÂntara \\ Universidade FEderal de LAVRAs / Departamento de AdMinistração e ECONOMIA, LAVRAS - MG, BRASIL
}

Eloísa helena de Souza Cabral

Universidade Federal de LaVRas / Departamento de AdMinistração e ECONOMia, LAVRAS - MG, Brasil

PAUlo de TARSO MuzY

UNIVERSIDAdE de SÃo PAUlo / REITORIA, SÃo PAULO - SP, BRASIL

José Roberto Pereira

Universidade Federal de LAVRas / Departamento de Administração e ECONomia, LAVRAS - MG, Brasil

\begin{abstract}
Resumo
Este artigo mostra que o conceito de mundo-da-vida (lebenswelt), em Jürgen Habermas, e a refutação da dicotomia fato x valor, em Hilary Putnam, podem esclarecer epistemologicamente o processo de avaliação em gestão social, que consiste em explicitar fatos, valores e seus respectivos significados intersubjetivamente compartilhados. Especificamente, apresentamos como instrumentos de experiência avaliativa o Mapa de Bens Públicos e o Mapa Semântico de Expectativas, Necessidades, Capacidades, Interesses e Representações (ENCIR), além de argumentarmos acerca de sua capacidade de explicitar comunicativamente os significados/as interpretações que emanam dos mundos-da-vida dos Públicos Constituintes. Argumentamos com Habermas que o mundo-da-vida é um fundamento epistemológico dos processos de avaliação na gestão social que considera a dialogicidade entre fatos e valores e, com Putnam, que esses elementos constitutivos da avaliação são imbricados e passíveis de discussão racional. Nessa perspectiva valorativo-comunicativa da avaliação, os processos devem ser construídos de acordo com as capacidades dos Públicos Constituintes e coproduzidos por meio de processos inclusivos, dialógicos e deliberativos validados intersubjetivamente, também atendendo às pretensões habermasianas de verdade, sinceridade/veracidade e correção normativa/legitimidade.
\end{abstract}

Palavras-chave: Mundo-da-vida. Fatos e valores. Avaliação. Gestão social.

\section{Facts, values and the life-world: epistemological arguments for evaluation in social management}

\section{Abstract}

This article aims to show that the concept of life-world (lebenswelt) in Jürgen Habermas, and the refutation of the dichotomy 'fact' $v$. 'value' in Hilary Putnam may account epistemologically for the evaluation process in social management, which consists of explicating facts, values and their respective meanings shared inter-subjectively. The article presents the Map of Public Goods and the Semantic Map of ENCIR (Expectations, Needs, Capabilities, Interests and Representations), which are instruments of evaluative experience, arguing on this instruments ability to communicatively explain the meanings/interpretations emanating from the life-world of Public Constituents. We argue with Habermas that life-world is an epistemological foundation of the evaluation procedures in social management that considers the dialogic relation between facts and values. With Putnam, we argue that these constituent elements are interwoven and subject to rational discussion. In this perspective, evaluative and communicative assessment processes must be built according to the capacities of the Public Constituents and co-produced by means of inclusive, dialogic and deliberative processes, validated inter-subjectively. This meets Habermas claims to truth, honesty/truthfulness and normative correction/legitimacy.

Keywords: Life-World. Facts and Values. Evaluation. Social Management.

\section{Hechos, valores y el mundo-de-la-vida: argumentos epistemológicos para evaluación en el ámbito de la gestión social}

\section{Resumen}

Este artículo muestra que el concepto de mundo-de-la-vida (lebenswelt), en Jürgen Habermas, y la refutación de la dicotomía hecho contra valor, en Hilary Putnam, pueden aclarar epistemológicamente el proceso de evaluación en la gestión social, que consiste en explicitar hechos, valores y sus respectivos significados compartidos intersubjetivamente. Específicamente, se presentan como instrumentos de experiencia evaluativa el Mapa de los Bienes Públicos y el Mapa Semántico de Expectativas, Necesidades, Capacidades, Intereses y Representaciones (ENCIR) y, además, se argumenta acerca de su capacidad de explicitar comunicativamente los significados/las interpretaciones que emanan de los mundos-de-la-vida de los Públicos Constituyentes. Se argumenta con Habermas que el mundo-de-la-vida es un fundamento epistemológico de los procesos de evaluación en la gestión social que considera la dialogicidad entre hechos y valores y, con Putnam, que estos elementos constituyentes de la evaluación están entrelazados y son pasibles de discusión racional. En esta perspectiva evaluativo-comunicativa de la evaluación, los procesos deben ser construidos según las capacidades de los Públicos Constituyentes y coproducidos por medio de procesos inclusivos, dialógicos y deliberativos validados intersubjetivamente, también teniendo en cuenta las reivindicaciones habermasianas de verdad, sinceridad/veracidad y corrección normativa/legitimidad.

Palabras clave: Mundo-de-la-vida. Hechos y valores. Evaluación. Gestión social. 


\section{INTRODUÇÃO}

Entre as peculiaridades do tema avaliação das ações sociais públicas desenvolvidas por instituições de interesse público (projetos sociais; terceiro setor; esfera pública; parcerias trissetoriais e outras), destaca-se a natureza singular desse espaço público, no qual se articulam atores sociais, expressam-se valores e realizam-se resultados colimados pela lente do desenvolvimento e da mudança social. Nessas ações, o argumento da intangibilidade dos valores reproduzidos sempre retorna como um impeditivo dos processos avaliativos, sendo considerados fatores que comprometeriam as avaliações objetivas.

Sob o aspecto prático, uma alternativa é conduzir as avaliações conferindo importância aos processos de reprodução de valores públicos, deliberação coletiva, participação democrática, gestão dialógica e esforços intersubjetivos dos diversos atores sociais. Entretanto, essa providência seria apenas uma "demanda estratégica" para o sucesso das finalidades avaliativas? Ou se trata do reconhecimento de um processo peculiar à comunicação entre os atores que possa se constituir na essência dos instrumentos avaliativos que incorporem a natureza da gestão social? Ou, ainda, como a peculiaridade expressa na comunicação de valores e na produção de bens de interesse público vincula a gestão social ao processo avaliativo e aos mundos-da-vida dos Públicos Constituintes?

Examinando a peculiaridade apontada acima para os projetos de ação social no espaço público, Cabral (2011) e Cabral e Muzy (2014) mostraram que os experimentos avaliativos desses projetos requisitam a consideração de fatos e de valores. Para os autores, valores e fatos concorrem ao mesmo requisito da racionalidade como atributo da possibilidade de sua identificação e comunicação. Essa abordagem supera o tratamento dos valores como atributos intangíveis e irracionais e os considera fundamentais para os processos avaliativos. Dessa forma, por exemplo, não há porque se recusar a identificar a reprodução do valor cooperação em uma ação social, a partir da percepção subjetiva e intersubjetiva dos indivíduos, alegando que essa subjetividade a torna irracional ou destituída de comparação interpessoal. Em verdade, esse valor orienta escolhas de indivíduos e pode ser incorporado em processos avaliativos a outras medidas comensuráveis de fatos determinados pela relevância do valor cooperação (HOUSE e HOWE, 2000; HOUSE, 2001; HOWE, 2002; CABRAL, 2011; CABRAL e MUZY, 2014).

O tratamento dos juízos de fato e dos juízos de valor como excludentes quanto à racionalidade e à possibilidade de comprovação é conhecido na literatura como "dicotomia fato x valor" e expressa-se na incomensurabilidade desses atos, considerados manifestações de juízos objetivos e subjetivos, respectivamente (HOUSE, 2001; HOUSE e HOWE, 2001; PUTNAM, 2002; 2008). De outra forma, os fatos são considerados verificáveis pela lógica ou observação empírica e os valores são considerados subjetivos e não verificáveis. Essa dicotomia remete à separação proposta por Immanuel Kant entre juízos analíticos e sintéticos e por David Hume entre questões de fato e relações de ideias (MARICONDA, 2006; PUTNAM, 2008). Lacey (2006, p. 252) acrescenta outras origens: "a ideia de que entre fato e valor existe não só uma 'distinção', mas também uma separação profunda, um abismo insuperável, ou uma 'dicotomia', originada no século XVII, especialmente nos escritos de Galileu, Bacon e Descartes". No século XX, essa dicotomia foi defendida intensamente pelos positivistas lógicos (PUTNAM, 2008) e teve implicações nas teorias administrativas e organizacionais (GUERREIRO RAMOS, 1981; SIMON, 1989; PROCÓPIO, 2015).

A influência da dicotomia fato $x$ valor possibilita que encontremos nos processos de avaliação no âmbito da administração, da administração pública, da política pública e da gestão social questões que não compreenderam a igualdade racional e objetiva dos juízos de fato e de valor. Essa separação tem efeito nos processos avaliativos que se prendem à objetividade dos fatos, descuidando da reprodução dos valores, como se a subjetividade subtraísse sua realidade e cientificidade. Foi contra essa perspectiva excludente que o filósofo Hilary Putnam $(2002 ; 2008)$ discorreu, mostrando a incoerência da dicotomia e o empobrecimento dos raciocínios que dela decorrem. No mais, as obras de Jürgen Habermas também sugerem (cf. ROUANET, 1989; FREITAG, 1989) possibilidades de superação da dicotomia rígida entre fatos, normas e valores, mesmo com discordâncias em relação à abordagem de Hilary Putnam no que se refere especialmente à separação entre normas e valores (HABERMAS, 1989; 2012a; PUTNAM, 2008). 
No intuito de ir além do impasse entre fatos e valores nos processos de avaliação, buscamos as contribuições do conceito de "mundo-da-vida" (lebenswelt) em Jürgen Habermas como um fundamento dos processos e instrumentos de avaliação na gestão social e, além disso, valemo-nos de argumentos que remetem à refutação da dicotomia fato x valor realizada por Hilary Putnam. Com isso, estabelecemos correspondência com os argumentos de diversos pesquisadores em gestão social que encontram em Habermas sustentação para uma forma de gestão gerencial dialógica nas esferas e nos espaços públicos (TENÓRIO, 2005; CANÇADO, PEREIRA e TENÓRIO, 2013) e com Putnam, que foi uma das referências de Cabral (2011) e Cabral e Muzy (2014), para desenvolverem os experimentos avaliativos que adotamos como referência.

Buscamos as contribuições do conceito de mundo-da-vida (lebenswelt) por considerar que os processos de avaliação são relacionais e comunicativos. Tendo por base que esse conceito, em suas diversas tradições, inclui as experiências cotidianas objetivas, subjetivas e intersubjetivas. Ao considerar o mundo-da-vida nos processos de avaliação destacamos a importância dos valores, comumente solapados pelos métodos positivistas. Entretanto, temos que ir além com Hilary Putnam e considerar que tantos valores quanto fatos podem ser considerados racionais e são "objetivamente" e "intersubjetivamente" verificáveis. Dessa forma, os instrumentos e processos de avaliação em gestão social devem comunicar transformações que impactam a vida das pessoas, permitindo abordar a avaliação como um vínculo (dicionário/linguagem) que traduz os atributos ou valores públicos em evidências e atitudes identificáveis na vida das pessoas.

Adiante, consideramos lócus de avaliação (em uma perspectiva sociológica) espaços e esferas compartilhados por atores da sociedade civil, do Estado e das organizações empresariais e, portanto, de acordo com Cohen e Arato (1992) e Habermas (1997b) compartilhados pelo mundo-da-vida (família, sociedade civil) e pelo sistema (Estado, mercado). É a partir disso que valores como pluralismo, igualdade participativa e inclusão serão tomados como fundamentais nos processos avaliativos em uma perspectiva que seja valorativa e comunicativa. Neste artigo, a diversidade de atores é marcada pelo conceito de Públicos Constituintes (CABRAL, 2011), que envolve diferentes atores e objetivos com suas "Expectativas", suas "Necessidades", suas "Capacidades", seus "Interesses" e suas "Representações" (ENCIR). Assim, "o conceito de Públicos Constituintes possibilita o reconhecimento dos diversos grupos sociais que se diferenciam por ENCIR, associando-se em termos dos valores relevantes que os projetos comunicam" (CABRAL e MUZY, 2014, p. 342).

Finalmente, este artigo objetiva comunicar como o conceito de mundo-da-vida (lebenswelt) em Jürgen Habermas e a refutação da dicotomia fato $x$ valor em Hilary Putnam podem esclarecer epistemologicamente o processo de avaliação em gestão social, que consiste em explicitar fatos, valores e seus respectivos significados intersubjetivamente compartilhados. Especificamente, apresentamos como possibilidade de experiência avaliativa coerente com isso o Mapa Semântico de ENCIR e o Mapa de Bens Públicos como capazes de explicitar comunicativamente os significados/as interpretações que emanam dos mundos-da-vida dos Públicos Constituintes.

Os argumentos se organizam em outras seções, além desta introdução. A parte seguinte apresenta o tema da avaliação em gestão social e a dicotomia fato $x$ valor. Depois abordamos o conceito de mundo-da-vida. Em seguida: i) refletimos acerca da relevância do mundo-da-vida (da linguagem e comunicação) na avaliação; ii) refletimos acerca dos valores, sua racionalidade e objetividade; e, por fim, iii) apresentamos um arcabouço analítico composto pelo Mapa de Bens Públicos e o Mapa Semântico de ENCIR. Nas considerações finais, apresentamos as conclusões e limitações deste artigo.

Para apresentar a literatura revisada, desenvolvemos o Quadro 1 com um esquema de análise teórica que apresenta conceitos centrais do artigo (temas e textos principais). 


\section{Quadro 1}

\section{Delimitação bibliográfica - esquema conceitual}

\begin{tabular}{|c|c|c|}
\hline \multirow{2}{*}{ Hilary Putnam } & Livro & $\begin{array}{l}\text { "O colapso da verdade e outros ensaios" - Putnam (2008); "The collapse of the fact/value } \\
\text { dichotomy" - Putnam (2002); "Reason, truth, and history" - Putnam (1981). }\end{array}$ \\
\hline & $\begin{array}{l}\text { Texto } \\
\text { complementar }\end{array}$ & $\begin{array}{l}\text { Walsh (2003); Lima (2013; 2014); Rodrigues (2013); Rodrigues e Oliveira (2013); Mello Junior } \\
\text { (2014). }\end{array}$ \\
\hline \multirow{2}{*}{$\begin{array}{l}\text { Jürgen } \\
\text { Habermas }\end{array}$} & Livro & $\begin{array}{l}\text { "Consciência moral e agir comunicativo" - Habermas (1989); "Direito e democracia: entre } \\
\text { facticidade e validade" - Habermas (1997a; 1997b); "Teoria do agir comunicativo" - Habermas } \\
\text { (2012a, 2012b); "Valores e normas: sobre o pragmatismo kantiano de Hilary Putnam" - } \\
\text { Habermas (2005). }\end{array}$ \\
\hline & $\begin{array}{l}\text { Texto } \\
\text { complementar }\end{array}$ & $\begin{array}{l}\text { Cohen e Arato (1992); Costa (1994); Freitag (1989; 2005); Lubenow (2013); Nobre (2011); } \\
\text { Rouanet (1987; 1989); Serva (1997); Vizeu (2005); Martino e Marques (2013); Paes de Paula } \\
\text { (2013); Pizzi (2006). }\end{array}$ \\
\hline \multicolumn{2}{|c|}{ Avaliação e modelos de avaliação } & $\begin{array}{l}\text { Boullosa e Rodrigues (2014); Mark (2001); Niemi e Kemmis (1999); Cabral (2011); Castellà e } \\
\text { Parés (2012); Faria (2005); House (2001); Howe (2002); House e Howe (2000; 2001); Worthen, } \\
\text { Sanders e Fitzpatrick (2004); Greene (2006); Papadopoulos e Warin (2007). }\end{array}$ \\
\hline \multicolumn{2}{|c|}{ Dicotomia fato $\mathrm{x}$ valor } & $\begin{array}{l}\text { Mariconda (2006); Joas (2001); Cabral e Muzy (2014); House (2001); Howe (2002); House e } \\
\text { Howe (2000; 2001); Lacey (2006); Pedro (2014). }\end{array}$ \\
\hline \multicolumn{2}{|c|}{ Gestão social } & $\begin{array}{l}\text { Cabral (2006; 2008; 2011); Alcântara (2015); Allebrandt, Siedenberg, Sausen et al. (2011); } \\
\text { Cançado, Pereira e Tenório (2013); Tenório (1998; 2005; 2013); Tenório, Villela, Dias et al. (2008); } \\
\text { Tenório, Dias, Villela et al. (2010); Pereira (2012). }\end{array}$ \\
\hline \multicolumn{2}{|c|}{ Valores públicos } & $\begin{array}{l}\text { Bozeman (2007); Andersen, Jørgensen, Kjeldsen et al. (2012); Jørgensen e Bozeman (2007); } \\
\text { Cabral (2006; 2008; 2011); House (2001); Howe (2002); House e Howe (2000; 2001). }\end{array}$ \\
\hline
\end{tabular}

Fonte: Elaborado pelos autores.

\section{AVALIAÇÃO, GESTÃO SOCIAL E A DICOTOMIA FATO X VALOR}

O termo avaliação possui diversas conotações e é usado das mais variadas formas, afinal, os processos de avaliação são singulares e formados por um emaranhado de fatores econômicos, sociais, políticos, culturais e éticos, sendo relevantes para o alcance de ações sociais que resultem na produção de bens públicos que impactem a qualidade de vida dos cidadãos (ROWE e FREWER, 2000; PAPADOPOULOS e WARIN, 2007). Por isso, a avaliação é essencial para aumentar a base informacional e, consequentemente, reduzir as incertezas das decisões.

No Brasil, há uma carência de trabalhos no que se refere à avaliação. Em políticas públicas, ela passou a ser compreendida em seu caráter de controle social e participação social somente a partir da década de 1980, e, mesmo assim, Faria (2005) destaca o viés técnico das avaliações. Essa lacuna de pesquisa em avaliação refletiu nos campos da administração pública e da gestão social. Em particular, no âmbito das organizações sociais, Cabral $(2011$, p. 1918) destaca essa carência:

[...] a avaliação e suas técnicas não estão suficientemente difundidas no campo das organizações sociais. Entre as razões de natureza geral, destacam-se: a incipiente profissionalização no setor e a constatação de que as práticas de avaliação não traduzem ainda a existência de uma cultura sistemática e difundida. Entre as razões específicas, citamos: a ausência de uma metodologia específica que apreenda o conteúdo valorativo das ações sociais e a insistência em importar técnicas e argumentos tanto da área pública quanto da área privada, sem o necessário diálogo que aponte as singularidades desse novo campo.

Isso se reforça quando consideramos organizações e ações que envolvem atores do Estado, do mercado e da sociedade civil o processo avaliativo se torna mais complexo e demanda outras formas, além da simples contagem de fatos e sua divulgação em relatórios técnicos. 
Conceitualmente, a avaliação pode ser entendida como "processo sistemático de obtenção de informações destinado a emitir juízos de valor a partir de critérios estabelecidos" (CASTELLÀ e PARÉS, 2012, p. 214). Segundo Boullosa e Rodrigues (2014, p. 153), a avaliação é "um processo de construção de significados ou de significâncias, no qual cada sujeito avaliador ou avaliado (diferentes atores com múltiplas realidades) deveria enfrentar um problema semântico relacionado à compreensão do significado da avaliação e dos seus processos". Para Worthen, Sanders e Fitzpatrick (2004, p. 35), é a "identificação, esclarecimento e aplicação de critérios defensáveis para determinar o valor ou mérito, a qualidade, a utilidade, a eficácia, ou a importância do objeto avaliado em relação a esses critérios". Finalmente, para Dias Sobrinho (2008, p. 193), "é produção de sentidos, prática social, portanto, intersubjetiva, relacional, aberta, polissêmica e carregada de valores, que põe em questão os significados dos fenômenos".

As finalidades da avaliação direcionam suas características, além do fato de que os motivos para avaliar são diversos, em destaque no âmbito de ações sociais: exigência dos agentes financiadores, testar a validade do projeto, identificar o impacto, fornecer dados sobre a possibilidade de continuação, buscar recursos, dentre outros (TENÓRIO, 2003; CASTELLÀ e PARÉS, 2012). Na gestão social, argumentamos que a finalidade da avaliação não é apenas teleológica, com relação a fins, mas, informacional e comunicativa. Essa concepção aproxima-se dos modelos de democratic evaluation (avaliação democrática), de MacDonald (1976 apud RYAN, 2004), deliberative democratic evaluation (avaliação democrática deliberativa), de House e Howe (2000), e communicative evaluation (avaliação comunicativa) de Niemi e Kemmis (1999).

MacDonald (1976 apud RYAN, 2004) e MacDonald e Kushner (2004 apud Ryan, 2004) destacaram a importância do caráter democrático da avaliação. Os trabalhos de House e Howe $(2000 ; 2001)$ propuseram a avaliação democrática deliberativa ressaltando os valores de inclusão, diálogo e deliberação. Para esses autores, a avaliação é vital para uma sociedade democrática. Por fim, Niemi e Kemmis (1999) apresentaram a avaliação comunicativa com base em Jürgen Habermas. Pelo exposto, a perspectiva avaliativa aqui discutida se aproxima mais deste último modelo (NIEMI e KEMMIS, 1999; RYAN, 2004). O Quadro 2 apresenta algumas das principais características das abordagens citadas.

\section{Quadro 2}

\section{Tipologia de comparação de gêneros de avaliação democrática}

\begin{tabular}{|c|c|c|c|}
\hline Teorias e práticas & Avaliação democrática & $\begin{array}{c}\text { Avaliação democrática } \\
\text { deliberativa }\end{array}$ & Avaliação comunicativa \\
\hline Fundações & $\begin{array}{l}\text { Democracia liberal } \\
\text { (John Locke) }\end{array}$ & $\begin{array}{l}\text { Democracia participativa } \\
\text { (Amy Gutmann) }\end{array}$ & $\begin{array}{l}\text { Democracia deliberativa } \\
\text { (Jürgen Habermas) }\end{array}$ \\
\hline Valores & Pluralismo e cidadania informada & $\begin{array}{l}\text { Democracia, justiça, } \\
\text { racionalidade }\end{array}$ & $\begin{array}{l}\text { Democracia, justiça, } \\
\text { emancipação }\end{array}$ \\
\hline Localização institucional & $\begin{array}{l}\text { Dentro das estruturas } \\
\text { institucionais formais }\end{array}$ & $\begin{array}{l}\text { Dentro das estruturas } \\
\text { institucionais formais }\end{array}$ & $\begin{array}{l}\text { Dentro de múltiplas } \\
\text { esferas públicas }\end{array}$ \\
\hline Metodologia & Estudo de caso & Métodos mistos & Métodos mistos críticos \\
\hline Conceitos-chave & $\begin{array}{l}\text { Confidencialidade, negociação, } \\
\text { acessibilidade }\end{array}$ & Diálogo, deliberação, inclusão & $\begin{array}{c}\text { Revelação; antecipação; } \\
\text { construção de comunicação } \\
\text { e parcerias }\end{array}$ \\
\hline Papel do avaliador & Mediador de informação & $\begin{array}{l}\text { Defensor dos princípios } \\
\text { democráticos, negociador }\end{array}$ & $\begin{array}{c}\text { Facilitador de determinado } \\
\text { tipo de conversa }\end{array}$ \\
\hline Papel participante & Significativa fonte de conhecimento & $\begin{array}{l}\text { Interesses presentes, } \\
\text { informar a avaliação }\end{array}$ & Proprietários do processo \\
\hline Justificação-chave & $\begin{array}{l}\text { Direito de saber } \\
\text { (transparência) }\end{array}$ & $\begin{array}{l}\text { Contribuir para a realização de } \\
\text { uma sociedade democrática }\end{array}$ & $\begin{array}{l}\text { Apoio efetivo para a } \\
\text { mudança social }\end{array}$ \\
\hline Práticas comunicativas & Relatório que aspira a ser bestseller & Relatório tradicional & $\begin{array}{c}\text { Estimular o discurso público, } \\
\text { permitindo redes de } \\
\text { comunicação }\end{array}$ \\
\hline
\end{tabular}

Fonte: Adaptado de Ryan (2004, p. 455). 
Como se observa no Quadro 2, esses modelos são focados em uma dimensão democrática da avaliação (GREENE, 2006). A perspectiva de Niemi e Kemmis (1999) e Kemmis e McTaggart (2000) tem base na teoria da ação comunicativa de Jürgen Habermas, no que diz respeito ao discurso público. Essa avaliação enfoca a construção de espaços de conversação pública onde os cidadãos podem debater e deliberar (RYAN, 2004). Essa questão pode ser relacionada aos critérios para avaliação de processos decisórios deliberativos desenvolvidos por Tenório, Villela, Dias et al. (2008) e Tenório, Dias, Villela et al. (2010) baseados no conceito de cidadania deliberativa (na gestão social) e que tem aproximação com a abordagem communicative evaluation (avaliação comunicativa) de Niemi e Kemmis (1999). Em Tenório, Villela, Dias et al. (2008) e Tenório, Dias, Villela et al. (2010) também se encontra a ideia de construção de um espaço de comunicação e deliberação no processo avaliativo, onde as decisões possuem legitimidade em decorrência da existência de processos de discussão, orientados pelos princípios da inclusão, do pluralismo, da igualdade participativa, da autonomia e do bem comum.

Contudo, apesar dos avanços, ainda são comuns nas teorias de avaliação as disputas entre aspectos qualitativos e quantitativos (ROWE e FREWER, 2000; HOUSE, 2001; HOUSE e ROWE, 2000; HOWE e ASHCRAFT, 2005) que refletem posições epistemológicas dicotômicas entre fatos e valores, conhecidas como a dicotomia fato x valor (PUTNAM, 2002; 2008). Como já destacado, essa dicotomia também impregnou os estudos das organizações sob a ótica positivista (TENÓRIO, 1998), considerando somente a dimensão dita objetiva das organizações e, com isso, os fatos (GUERREIRO RAMOS, 1981). Este autor afirmou que: "a dicotomia entre valores e fatos é falsa, na prática, e, em teoria tende a produzir uma análise defectiva" (GUERREIRO RAMOS, 1981, p. 29). Mariconda (2006) considera que a dicotomia surge quando os valores ficam restritos a questões subjetivas e preferências individuais, assim, não apresentam significado cognitivo. Para Mariconda (2006, p. 453-454) a desconsideração dos valores tem base na ideia do predomínio de uma racionalidade instrumental: "[a] desqualificação da esfera do valor faz parte da estratégia do cientificismo de afirmação da universalidade da razão instrumental com o objetivo de ocultar o caráter valorativo da ideia fundamental que orienta a tecnociência atual: o controle (domínio) da natureza".

Putnam (2008) assume que tanto fatos quanto valores podem ser considerados verdadeiros, racionais e objetivos, para isso, afirma que entre os dois há entanglement (imbricação): os valores não são antagônicos aos fatos, são apenas peculiares e diferentes (LACEY, 2006; PUTNAM, 2008). Segundo Putnam (2008, p. 39), a "visão positivista lógica original era de que um 'fato' era algo que podia ser certificado por mera observação e até mesmo por um mero relato de uma experiência sensorial". Como efeito disso, consideravam-se "os valores (ética, política, direito) como assunto privado (subjetivo) e, portanto, não podem ser questionados ou discutidos racionalmente" (RODRIGUES, 2013, p. 77).

Sobre a importância de superar essa visão da dicotomia fato x valor, observamos em Gaulejac (2007, p. 293-294) que a gestão costuma "apoiar-se no registro material [...] a razão pela qual ela não fornece respostas satisfatórias sobre o registro simbólico". E, para ele é na linguagem que o homem comunica, elabora e internaliza as ordens simbólicas de sua ação. Consequentemente, é preciso que a gestão se liberte das coisas (fatos em sentido restrito) para definir um sentido comum para suas ações. Finalmente, o autor coloca: "espera-se da gestão esta coerência [...] entre o vivido e o conceito, entre o prescrito e o realizável, entre a cifra e o que ela mede" (GAULEJAC, 2007, p. 297) - vínculo estabelecido, em parte, por meio da superação da dicotomia fato x valor.

House e Howe (2000; 2001), Howe (2000), House (2001) e Howe e Ashcraft (2005) desenvolveram trabalhos visando a superar as dicotomias entre fatos e valores, tanto como pressuposto teórico quanto como abordagem metodológica. Para esses autores, fatos e valores não habitam "reinos" diferentes e os valores podem ser avaliados racionalmente. Para House e Howe (2001) a melhor compreensão possível é que fatos e valores representam um continuum e em relatórios de avaliação serão encontrados de forma intrincada. Com esse posicionamento, eles desenvolveram um modelo de avaliação democrática deliberativa (já citado) que indica a importância dos valores (em especial, inclusão, diálogo e deliberação) nos processos de avaliação.

De modo coerente com essas discussões, Cabral (2006; 2008; 2011) apresenta a gestão social como uma forma de superar a dicotomia fato $x$ valor, pois atuaria como produtora de bens públicos e reprodutora de valores. No escopo da avaliação, a autora concebe que "os valores reproduzidos no espaço público são tomados como fundamentais" e que "a explicitação dos valores transmitidos e os benefícios gerados permitem que o processo de avaliação seja um agente de comunicação eficiente dos resultados, que passam a se revestir de significado objetivo para aqueles públicos [envolvidos]" (CABRAL, 2011, p. 1937). Nesse artigo, a autora também faz críticas à dicotomia fato x valor:

A dicotomia fato $x$ valor forçava a apresentação dos fatos como observáveis, enquanto os valores eram tratados como manifestações individuais, ou trans-substancializações coletivas, relativas a situações 
subjetivas e a julgamentos incomensuráveis entre si, que induziam os indivíduos a manifestarem classificações e preferências. Putnam e Walsh mostraram que, apesar da distinção metodológica entre fatos e valores, não se pode abordar a realidade com um critério que "fatora" os achados em uma "parte descritiva", tomados como valores, e uma "parte avaliativa", tomada como fato. Isso porque as ações dos homens em sociedade desenvolvem sociabilidades a partir de condições, escolhas e propósitos, parâmetros nos quais os fatos são valorizados como fatos à medida que expressam os valores determinados socialmente (CABRAL, 2011, p. 1917-1918).

Nos espaços avaliativos, Cabral (2011) identifica a presença de diversos Públicos Constituintes relacionados ao Estado (Poder Público), ao mercado (setor empresarial), à sociedade civil e às comunidades: beneficiários, doadores, voluntários, empregados, instituidores e outros. Estes são grupos de indivíduos que atuam de diferentes modos de apropriação ou manifestação de valores: "Expectativas", "Necessidades", "Capacidades", "Interesses" e "Representações" (ENCIR). ENCIRs são conteúdos significativos cotidianamente expressos pelos públicos em sua interpretação dos fatos e valores ao fruírem bens públicos. Nesse sentido, argumentaremos que as ENCIRs desempenham um papel fundamental na ação comunicativa dos públicos e sua explicitação no processo avaliativo é vital para o desenvolvimento da avaliação. Por isso, Cabral e Muzy (2014) argumentam que os fatos e valores devem ser incorporados na racionalidade do diálogo e comunicados como complementares.

Na gestão social, alguns trabalhos se atentaram à questão da avaliação (TENÓRIO, VILLELA, DIAS et al., 2008; TENÓRIO, DIAS, VILLELA et al., 2010; BOULLOSA e RODRIGUES, 2014). A principal contribuição de Tenório, Villela, Dias et al. (2008) e Tenório, Dias, Villela et al. (2010) foi a apresentação dos critérios de avaliação de processos decisórios deliberativos anteriormente destacados e utilizados em uma série de pesquisas empíricas (ALLEBRANDT, SIEDENBERG, SAUSEN et al., 2011; DIAS, 2012). No campo da administração pública, alguns autores atestaram a carência de parâmetros adequados para a avaliação da participação deliberativa das pessoas no espaço público (ROWE e FREWER, 2000; PAPADOPOULOS e WARIN, 2007).

Finalmente, as discussões apresentadas são importantes para a gestão social em decorrência da necessidade de desenvolver formas de avaliação menos tecnocráticas e mais comunicativas e valorativas, especialmente para organizações e ações desenvolvidas em um lócus compartilhado pelo "mundo-da-vida" e pelo "sistema" - como o terceiro setor apresentado por Cabral (2011) ou mesmo a noção de esfera pública de Tenório (2005) ou de espaço compartilhado de Pereira (2012). Nesses espaços e esferas, há necessidade de considerar, além dos fatos (o que tradicionalmente, sob a ótica positivista, é foco das avaliações), os valores públicos e democráticos reproduzidos nos e pelos mundos-da-vida dos diversos Públicos Constituintes.

\section{A VOLTA DO MUNDO-DA-VIDA: PLANO DE FUNDO DAS PRÁTICAS AVALIATIVAS}

O termo mundo-da-vida (lebenswelt) está presente na tradição filosófica do século XX. Foi primeiro utilizado por Edmund Husserl e "ganhou várias apropriações e variações, tanto na filosofia, em particular nos trabalhos de Heidegger e Habermas, quanto na sociologia de Schütz, Luckmann e Berger" (MARTINO e MARQUES, 2013, p. 2). De forma geral, em diversas abordagens da fenomenologia, da hermenêutica e da filosofia analítica (DOMINGUES, 1999). Habermas (1996) afirma que Husserl buscou no mundo-da-vida a fundação do sentido da ciência, da prática da vida cotidiana e da experiência.

O conceito de mundo-da-vida foi consolidado em Habermas em uma mistura da fenomenologia, do interacionismo simbólico e da filosofia linguística (DOMINGUES, 1999; VANDENBERGHE, 2011). Nesse processo, Habermas (2012b) procura romper com a "filosofia da consciência" na qual o conceito de mundo-da-vida se prendia em direção à intersubjetividade (modelo comunicativo da razão). Assim, Habermas (2012b) vai destacar a unidimensionalidade do conceito husserliano (fenomenológico) de lebenswelt.

Um dos principais pontos de tensão entre Husserl e Habermas deriva do papel atribuído à experiência dentro da abordagem fenomenológica. Se em Husserl a experiência individual pode estabelecer uma mediação entre o sujeito particular e o mundo, em Habermas a experiência individual (meditação, reflexão subjetiva) só consegue ser mediadora se for submetida a um teste intersubjetivo de validade, realizado não sob a forma de uma troca linguageira ingênua, mas sob a forma do discurso. Habermas critica Husserl de permanecer atado à filosofia da consciência, enquanto ele privilegia o agir intersubjetivo (MARTINO e MARQUES, 2013, p. 10). 
Contudo, Husserl é um autor importante para o conceito de mundo-da-vida de Habermas, junto com Alfred Schütz, Peter Berger e Thomas Luckmann. Mesmo assim, apesar do caminho em direção à intersubjetividade nesses três autores (Schütz, Berger e Luckmann), para Habermas (1990) eles não rompem com o paradigma do sujeito (da consciência). Consoante Habermas, tanto Husserl quanto Schütz, Berger e Luckmann, em sua descrição fenomenológica, não apreendem a alteridade da experiência cotidiana, isto é, a intersubjetividade dos atores sociais.

Além de apresentar uma visão do mundo-da-vida reformulada por uma teoria da comunicação, em Teoria do Agir Comunicativo, o autor compreende a sociedade mediante um modelo dual: a esfera sistêmica e a esfera do mundo-da-vida. Assim, Habermas (2012b, p. 220) concebe a sociedade simultaneamente na perspectiva do participante e do observador: "proponho que a sociedade seja concebida, ao mesmo tempo, como mundo da vida e como sistema". Ou seja, sistemas funcionais (Estado e mercado) e mundo-da-vida, regidos por códigos, racionalidades, lógicas e demandas específicas.

Para Habermas (2012b) o mundo-da-vida se relaciona com o saber cultural, as normas e os valores: "cada mundo da vida equipa os seus membros com um estoque comum de saber cultural, de padrões de socialização, valores e normas" (HABERMAS, 2001, p. 193). De outra forma, é no mundo-da-vida que compartilhamos intersubjetivamente experiências culturais e histórias formando um consenso de plano de fundo, um "horizonte no qual os que agem comunicativamente se encontram desde sempre" (HABERMAS, 2012b, p. 218, grifo do autor). Assim, para Habermas (1997a; 2002; 2012a) o mundo-da-vida é estruturado pela cultura (reserva de conhecimento na qual os participantes buscam suas interpretações), sociedade (as ordens legítimas) e personalidade (as competências que possibilitam ao sujeito falar e agir), possuindo como medium a linguagem.

O mundo da vida configura-se como uma rede ramificada de ações comunicativas que se difundem em espaços sociais e épocas históricas; e as ações comunicativas, não somente se alimentam das fontes das tradições culturais e das ordens legítimas, como também dependem das identidades dos indivíduos socializados. Por isso, o mundo da vida não pode ser tido como uma organização superdimensionada, à qual os membros se filiam, nem como uma associação ou liga, na qual os indivíduos se inscrevem, nem como uma coletividade que se compõe de membros. Os indivíduos socializados não conseguiram afirmar-se na qualidade de sujeitos, se não encontrassem apoio nas condições de reconhecimento recíproco, articuladas nas tradições culturais e estabilizadas em ordens legítimas e vice-versa. A prática comunicativa cotidiana, na qual o mundo da vida certamente está centrado, resulta, com a mesma originariedade, do jogo entre reprodução cultural, integração social e socialização (HABERMAS, 1997a, p. 111-112, grifo do autor).

Mesmo com essa colocação, Cohen e Arato (1992) propuseram que a sociedade civil corresponde à dimensão institucional do mundo-da-vida (COSTA, 1994). A partir daí, tornou-se comum o modelo tripartite originado da dualidade entre mundo-da-vida e sistema: Estado e mercado (sistema) e sociedade civil (mundo-da-vida). Adiante, aceitando essa ideia, Habermas (1997b) coloca que a sociedade civil é formada por movimentos sociais, associações e organizações que selecionam e capturam os problemas sociais e os condensam na esfera pública - enraizada no mundo-da-vida.

Uma inovação de Habermas (2012b) é apresentar o mundo-da-vida como complementar ao agir comunicativo. Para o autor, a "racionalidade comunicativa exprime-se na força unificadora da fala orientada ao entendimento mútuo, discurso que assegura aos falantes envolvidos um mundo da vida intersubjetivamente partilhado" (HABERMAS, 2004, p. 107). Com isso, Habermas (2012a) analisa a racionalidade comunicativa pelo fio do entendimento linguístico enquanto mecanismo de coordenação da ação.

Habermas (2012a) apresenta relações entre pretensões de validade, mundos (social, objetivo e subjetivo), ação comunicativa e mundo-da-vida - esse modelo denota sua visão da pragmática formal. Para o autor, somente o agir comunicativo pressupõe a linguagem como medium do entendimento, onde pelo menos dois sujeitos referem-se a algo no mundo objetivo, social e subjetivo. Com isso, pode-se definir o agir comunicativo como as interações nas quais "o acordo alcançado em cada caso [mede-se] pelo reconhecimento intersubjetivo das pretensões de validez" (HABERMAS, 1989, p. 79). Sendo pretensões de verdade, correção normativa (legitimidade) e sinceridade (veracidade): "conforme se refiram a algo no mundo objetivo (enquanto totalidade dos estados de coisas existentes), a algo no mundo social comum (enquanto totalidade das relações interpessoais legitimamente reguladas de um grupo social) ou a algo no mundo subjetivo próprio (enquanto totalidade das vivências a que tem acesso privilegiado)" (HABERMAS, 1989, p. 79). 
Fazendo contraponto, no sistema os mecanismos de coordenação das ações são estratégicos (uma ampliação do modelo teleológico), em termos habermasianos: o poder administrativo (Estado) e o dinheiro (sistema econômico). Adiante, a concepção de sistema em Habermas (2012b) parte de Niklas Luhmann e Talcott Parsons. Habermas (2012b) destaca a importância da teoria dos sistemas ao afirmar que a coesão social não é obtida apenas por meio de processos comunicativos: "sociedades modernas são integradas não somente através de valores, normas e processos de entendimento, mas também sistemicamente, através de mercados e do poder administrativo. Dinheiro e poder administrativo constituem mecanismos da integração social” (HABERMAS, 1997a, p. 61-62).

Consequentemente, a ação comunicativa se diferencia da ação estratégica. A primeira reproduz o mundo-da-vida enquanto a segunda se efetiva nos sistemas. Mesmo assim, são necessárias para a reprodução simbólica (ação comunicativa) e material (ação instrumental e estratégica) da sociedade. Logo, o "fundamental para Habermas é que cada uma dessas racionalidades não extrapole seus domínios próprios" (NOBRE, 2011, p. 58). Entretanto, o diagnóstico é de que existe desequilíbrio na integração ("colonização do mundo-da-vida pelo sistema"), pois, "embora os sistemas econômico e administrativo sejam necessários para a coordenação de sociedades complexas, há limites para o uso da razão funcionalista. Se esses limites não são respeitados, o efeito colateral é a reificação das relações sociais" (ANDREWS, 2011, p. 65). Nesse sentido, a colonização se torna uma questão investigada por Jürgen Habermas.

A colonização do mundo da vida vai aniquilando os contextos capazes de comunicação, a integração social por meio do entendimento linguístico. As interações regidas pelos meios sistêmicos acabam exonerando a ação comunicativa como modo de coordenação da ação, substituída por meios de comunicação deslinguistizados; uma instrumentalização dos recursos comunicativos do mundo da vida pelos imperativos sistêmicos. $O$ engate institucional dos mecanismos de integração sistêmica no mundo da vida acaba solapando, burocraticamente, o espaço da formação discursiva da vontade coletiva, o espaço da opinião pública (LUBENOW, 2013, p. 170).

Segundo Rouanet (1987, p. 540), quando o sistema tenta colonizar o mundo-da-vida, a racionalidade da reprodução simbólica (comunicativa) vai sendo crescentemente substituída pela racionalidade instrumental, e, com isso, surgem diversas patologias sociais, como anomia social, alienação e reificação (VANDENBERGHE, 2011). Habermas (2012b, p. 597) estabelece que a racionalização unilateral e a reificação da prática comunicativa é fruto da penetração da racionalidade das esferas econômica (pelo dinheiro) e administrativa (pelo poder) em esferas de ação "que se especializam na tradição cultural, na integração e na educação social".

No entanto, em Direito e democracia, de 1992, Habermas (1997b) concebe no ínterim de uma reformulação da esfera pública a possibilidade dos fluxos comunicacionais oriundos do mundo-da-vida influenciarem os sistemas administrativos e econômicos, afirmando que "é necessário que os impulsos do mundo da vida possam influir no autocontrole dos sistemas funcionais" (HABERMAS, 2000, p. 505). No novo escopo, Habermas (1997b) defende a concepção de que as demandas do mundo-da-vida devem, por meio de um processo democrático-deliberativo, orientar os sistemas. Assim, uma ampliação desse modelo (oportuna para a gestão social) nos permite pensar as tensões entre o sistema, o mundo-da-vida, seus atores, suas lógicas e suas instituições, como defende Alcântara (2015).

Nosso principal argumento neste artigo caminha na direção do conceito de mundo-da-vida (lebenswelt) e sua relação com a linguagem, a comunicação e a intersubjetividade (sentido pragmático-linguístico) pode ajudar a avançar nas discussões sobre a avaliação em gestão social e colaborar para a proposta de uma perspectiva valorativa e comunicativa. Além disso, ao não descartar o "sistema" podemos, em uma perspectiva institucional, considerar o lócus das avaliações espaços/esferas compartilhadas por atores do Estado, mercado e sociedade civil. Por isso, nossa proposta engloba os ambientes de avaliação dos modelos avaliação democrática deliberativa, de House e Howe (2000; 2001), que destaca estruturas institucionais formais (sistema), e avaliação comunicativa, de Niemi e Kemmis (1999), que destaca múltiplas esferas públicas e o mundo-da-vida. Também ampliamos a concepção de Habermas ao colocar zonas de integração, cooperação e conflito entre mundo-da-vida e sistema (SERVA e ANDION, 2004; TENÓRIO, 2005; ALCÂNTARA, 2015). Por isso, para Alcântara (2015, p. 295) a gestão social não deve "voltar-se apenas para o mundo-da-vida" desconsiderando o sistema, mas, compreender "as relações entre estas esferas constituintes da sociedade moderna, suas tensões"; ou ainda, "a gestão social pode ser capaz de estabelecer as pontes [entre mundo-da-vida e sistema] orientadas pela comunicação, pelo diálogo, isto é, pelo movimento e coordenação democrática dessas relações" (ALCÂNTARA, 2015, p. 76). 
Finalmente, apresentamos neste artigo a necessidade de considerar os valores (públicos) nesses processos como orientação normativa que representa uma crítica ao predomínio da razão instrumental e estratégica sobre as experiências cotidianas e que coaduna processos avaliativos apenas focados em resultados, eficiência e desempenho mensurados por fatos. Um contraponto a isso é fornecido, segundo Pizzi (2006), pelo próprio conceito de mundo-da-vida, por seu potencial de crítica da razão instrumental desde os textos de Husserl até Habermas.

\section{AVALIAÇÃO: FATOS, VALORES, MUNDO-DA-VIDA E SISTEMA}

Na literatura internacional e nacional, alguns pressupostos deste artigo já foram debatidos: i) a dicotomia fato x valor obscurece concepções epistemológicas de pesquisa e empobrece o processo avaliativo (SEN, 1999; 2000; WALSH, 2003; HOUSE e HOWE, 2001; CABRAL, 2011; CABRAL e MUZY, 2014); e ii) a gestão social oferece argumentos para superar a dicotomia fato $x$ valor (CABRAL, 2006; 2008; 2011; CABRAL e MUZY, 2014). Logo, temos uma base sólida de discussão da qual partimos. Não obstante, esses pressupostos podem ser problematizados em outros momentos, deixando de ser autoevidentes. Avançamos nas subseções seguintes desenvolvendo três momentos centrais deste artigo:

1. O conceito de mundo-da-vida é relevante para a construção de práticas avaliativas que cumpram mediante a linguagem orientada ao entendimento, papel informacional e comunicacional;

2. Há necessidade da gestão social superar a dicotomia entre fatos e valores e considerar ambos racionalmente nos processos de avaliação; e

3. A avaliação em gestão social deve ser capaz de explicitar fatos e valores do/no mundo-da-vida dos diversos Públicos Constituintes, como reveladora de significados projetados no espaço público. Nisso é que concorrem o Mapa de Bens Públicos e o Mapa Semântico de ENCIR.

No final, apresentaremos uma representação gráfica do processo de avaliação que considere os mundos-da-vida dos diversos Públicos Constituintes e os sistemas sociais.

\section{MUNDO-DA-VIDA, LINGUAGEM E COMUNICAÇÃO NO PROCESSO AVALIATIVO}

A linguagem se constitui em Habermas (1989; 2012a; 2012b) como medium para o entendimento. Nesse norte, a linguagem e a comunicação se tornam fundamentais nas práticas de gestão e avaliação, principalmente se consideramos ações voltadas ao entendimento e esclarecimento. Nesse sentido, o empreendimento de Habermas sempre foi reconhecer a possibilidade de uma dimensão intersubjetiva da realidade social onde, no diálogo livre de coerção, os atos de fala demandam pretensões de validade. Assim, com a pragmática formal, Habermas substitui a "consciência transcendental kantiana - tida como fonte e condição de possibilidade de relações sociais - por práticas de uma comunicação que se realiza mediante linguagem comum" (SIEBENEICHLER, 2012, p. xix).

As pretensões de validade (verdade, sinceridade e legitimidade/correção normativa; em alguns textos Habermas trata também da inteligibilidade) são fundamentais em processos de avaliação, pois somente com o reconhecimento intersubjetivo é que os atores sociais, Públicos Constituintes, podem aceitar como legítima a construção dos instrumentos e indicadores - quando nesses processos eles se submeterem "aos critérios públicos da racionalidade do entendimento" (HABERMAS, 1990, p. 82-83). Dessa forma, constitui-se o agir comunicativo, ou ação comunicativa, especialmente, em seu sentido forte, isto é, "quando se pode criticar um ato ilocucionário sob todas as três pretensões de validade" (HABERMAS, 2002, p. 119). Adiante, se as pretensões são aceitas pelo outro (alter), tem-se o entendimento (verständigung) da: "união dos participantes da comunicação sobre a validade de uma exteriorização" (HABERMAS, 2012b, p. 221), passo necessário para o consenso (einvenständnis) ou acordo - "reconhecimento intersubjetivo da pretensão de validade que o falante une a uma exteriorização" (HABERMAS, 2012b, p. 221).

Isso significa que, durante a avaliação, quando não se chega ao consenso, isto é, quando os proferimentos forem problematizados, os Públicos Constituintes podem "abandonar as certezas preestabelecidas e ingressar em um processo de construção argumentativa da validade em questão" (OLIVEIRA, AYRES e ZOBOLI, 2011, p. 368). As deliberações advindas desse processo 
argumentativo são essenciais na construção do ambiente avaliativo que tem por horizonte um contexto compartilhado. Nesse sentido, o ambiente avaliativo da gestão social (CABRAL, 2011; HOUSE e HOWE, 2001) pode aproximar-se de uma comunidade de comunicação em que "inquiridores (falantes) reconhecem a sua experiência reflexiva nos processos de argumentação como orientação normativo-crítica geral dos discursos produzidos no mundo da vida" (HERDY, 2006, p. 47-48). Não há, dessa forma, processo avaliativo sem comunicação e sem linguagem. Logo, destacamos a importância dessas categorias nos processos avaliativos e o mundo-da-vida como instância compartilhada.

O "mundo da vida" é o mundo edificado nos/sobre dados na forma de signos e significados apreendidos pela consciência intersubjetiva, que neles encontra a matéria-prima das interpretações que efetivamente vão constituir a experiência de vida, o "mundo vivido". Não há "mundo da vida" sem significados; não há "mundo da vida" sem comunicação (MARTINO e MARQUES, 2013, p. 7).

Dito isso, em um processo de avaliação, a comunicação com todos os públicos se torna fundamental. Interessantemente, a própria expressão comunicação tem uma dimensão próxima ao conceito de mundo-da-vida, afinal, para Martino e Marques (2013), comunicar relaciona-se com "tornar comum e compartilhar". Como é por meio da linguagem que significamos o mundo em que vivemos e esse significado orienta a ação das pessoas (VIZEU, 2005), é importante considerar que os processos de avaliação devem ser capazes de explicitar tanto os fatos quanto os valores que fazem parte da vida cotidiana dos indivíduos.

As considerações supracitadas se aproximam dos textos de Niemi e Kemmis (1999) e Ryan (2004), que defendem a importância da comunicação nos processos avaliativos por meio da conversa e da reflexão entre as diversas partes interessadas no processo. Na prática do campo da avaliação, autores como Rowe e Frewer (2000) e House e Howe (2001) já alertaram sobre a importância dos "atingidos" por um processo avaliativo participarem efetivamente da construção dos meios de avaliação e a aceitação pública do mesmo. Com isso, supera-se comunicativamente a ideia de que a avaliação seja apenas uma ação com relação a fins - estratégica e monológica - realizada por tecnoburocratas. Destacamos que o termo atingido (tal como participante, ator ou Público Constituinte) destaca que o processo de avaliação não depende somente de pressupostos epistemológicos, mas se relaciona com a prática concreta de avaliações que são realizadas em seus contextos sócio-históricos e políticos. Nisso, todo processo de avaliação possui tanto dimensões epistemológicas no que diz respeito à construção do conhecimento (envolvendo relações entre sujeito-objeto, e, sujeito-sujeito em uma perspectiva habermasiana) quanto dimensões políticas no sentido amplo, envolvendo, assim, tanto a influência política, relações de interesses e interações Estado-empresa-sociedade.

No âmbito da gestão social, defendemos que as ações de avaliação demandam o agir comunicativo, para que sejam capazes de reproduzir valores do mundo-da-vida na interação no espaço público com os diversos Públicos Constituintes e os fatos produzidos. Lembrando:

O conceito de gestão social encontra fundamento na teoria da ação comunicativa de Jürgen Habermas, pois é entendida como um processo dialógico, no qual todos os participantes da ação admitem sua validade, ou seja, a verdade é um acordo alcançado por meio da discussão crítica, da apreciação intersubjetiva. Sob a atuação da ação comunicativa, nesse tipo de ação o indivíduo busca motivar o outro para que esse concorde com o seu argumento, sendo a linguagem utilizada como fonte de integração social (TENÓRIO, KRONEMBERGER e LAVINAS, 2014, p. 230).

Como os argumentos de Habermas (2012a; 2012b) possuem como núcleo o uso da linguagem como meio fundamental de coordenação das ações, dos debates na esfera pública e da democracia nas sociedades complexas, os processos de avaliação são, nesse sentido, momentos importantes de direito à palavra e de expressão pragmática-moral dos Públicos Constituintes. Mais à frente, apresentaremos que essa comunicação pode ser parcialmente captada (compreendida) mediante o Mapa de Bens Públicos e o Mapa Semântico de ENCIR, os quais organizam os significados correlatos entre os mundos-da-vida e a sistematização avaliativa, isto é, ela reúne fatos e valores como igualmente importantes.

\section{RACIONALIDADE E A DICOTOMIA FATO X VALOR NA AVALIAÇÃO}

Neste tópico, argumentamos que é necessário superar a dicotomia entre fatos e valores no âmbito das práticas da gestão social e, consequentemente, fatos e valores devem ser considerados racionalmente nos processos avaliativos das experiências 
de gestão gerencial dialógica. Apresentamos e diferenciamos as perspectivas de Habermas e Putnam. Antes, a questão que colocamos é: Quais são os valores relevantes para as ações/práticas no âmbito da gestão social?

Para House e Howe (2001), os processos avaliativos devem ser inclusivos, dialógicos e deliberativos, assim, inclusão, diálogo e deliberação são valores com os quais todos devem estar envolvidos na busca de um acordo válido. Com a presença de todos os públicos interessados, os valores devem ser considerados e discutidos, pois é somente por esse caminho que se pode chegar a conclusões válidas - sujeitas a crítica e análise racional (HOUSE e HOWE, 2001). Em sentido próximo, Niemi e Kemmis (1999) destacam que a ação comunicativa fornece elementos para uma situação de avaliação democraticamente constituída. Finalmente, os processos de inclusão, diálogo e deliberação são pilares dessa concepção avaliativa, pois "estes Públicos Constituintes se identificam por diferentes valores determinando expectativas, necessidades, capacidades, interesses e representações sociais" (CABRAL, 2008, p. 30).

No mais, sobre os valores do espaço avaliativo, também estabelecemos relação com os critérios de avaliação de processos decisórios deliberativos elaborados por Tenório, Villela, Dias et al. (2008) e Tenório, Dias, Villela et al. (2010): processos de discussão, inclusão, pluralismo, igualdade participativa, autonomia e bem comum - alguns presentes nos trabalhos de House e Howe (2001) e Niemi e Kemmis (1999). E, ainda, com os atributos do espaço público de Cabral (2011): visibilidade, controle, defesa social, democratização, representatividade de interesses coletivos, sustentabilidade, cultura pública, autonomia, universalidade, qualidade e efetividade. Igualmente, Boullosa e Rodrigues (2014) afirmam que a avaliação deve ser inclusiva e deve considerar os atores que a integram são mobilizados ou afetados pelo objeto da avaliação. Os valores públicos (como democracia, bem comum, diálogo e interesse público - enfim, valores republicanos) descritos por Jørgensen e Bozeman (2007) também são coerentes em relação a essa proposta. Finalmente, os critérios/valores apresentados são importantes para o paradigma deliberativo de Habermas (2008, p. 11), no que se refere às suas referências a inclusão, igualdade, publicidade, transparência e troca de argumentos:

O paradigma deliberativo oferece como seu ponto de referência empírico principal um processo democrático que supostamente deveria gerar a legitimidade através de um procedimento de formação da opinião e da vontade que garante (a) publicidade e transparência para o processo deliberativo; (b) inclusão e igual oportunidade para a participação; e (c) uma pretensão justificada para resultados obtidos através da troca de argumentos.

Em resumo, considerando os valores presentes na literatura nacional e internacional no âmbito das ações sociais como valores relevantes sob a ótica de uma teoria dos valores públicos e que, portanto, podem ser pontos de referência inicial, indicamos os seguintes: democracia, autonomia, diálogo, igualdade, inclusão, interesse público, pluralismo, sustentabilidade, cooperação, consenso, deliberação, liberdade, civismo, aprendizagem, bem comum, discussão e participação (BOZEMAN, 2007; JØRGENSEN e BOZEMAN, 2007; TENÓRIO, VILLELA, DIAS et al., 2008; TENÓRIO, DIAS, VILLELA et al., 2010; ANDERSEN, JØRGENSEN, KJELDSEN et al., 2012; CABRAL, 2011). Sobre a democracia e o interesse público, House e Howe (2001) apresentam que:

[...] os avaliadores devem ser defensores da democracia e do interesse público. Democracia visa incorporar todos os interesses legítimos. Do nosso ponto de vista, o interesse público não é estático e, muitas vezes, não é inicialmente identificável, porém emerge (ou deveria emergir) por meio de alguns procedimentos democráticos, devidamente respeitados por aqueles que na avaliação desempenham um papel. (HOUSE e HOWE, 2001, p. 138, tradução nossa).

Neste artigo, os valores listados são os considerados para nortear, no âmbito das ações/práticas da gestão social, a superação da dicotomia fato $x$ valor (outros valores podem emergir das relações entre avaliadores, pesquisadores e "atingidos"). Essa superação se faz, inegavelmente, pela comunicação de valores e fatos. Dessa forma, por meio da linguagem e considerando o significado (de fatos e valores), é possível rejeitar a dicotomia. Isso corrobora a afirmação de Putnam (1981) de que sem valores não há fatos: estes são carregados de valores e os valores são carregados de fatos. De forma semelhante, House e Howe (2001, p. 150, tradução nossa) afirmam: “As afirmações de fatos e valores se encontram em um contínuo em que são misturados em afirmações de avaliação [...]. Tanto os fatos como os valores podem ser determinados por meio de procedimentos racionais" - consequentemente, os valores estão associados a qualquer avaliação e devem ser considerados. 
Putnam (2008) e Habermas (2004) apresentam que o significado se encontra nas relações cotidianas e mediadas pela linguagem (LIMA, 2013). Nesse ponto, os autores são consensuais, compartilhando um pragmatismo kantiano (HABERMAS, 2004; PUTNAM, 2008). Além disso, Habermas (2007, p. 45) considera que "se os significados 'não estão na cabeça', como quer Putnam, só a linguagem pode ser o veículo intersubjetivo pelo qual esses significados tomam corpo". Uma das diferenças entre as propostas de Habermas e Putnam se refere à separação que Habermas faz entre normas e valores, em que, pressupõe objetividade e validade universal apenas para as primeiras (HABERMAS, 1997a; 2012a). Além disso, para Habermas, as normas são obrigatórias, os valores, não; as normas possuem pretensões de validade universal e os valores apenas validade particular; normas são interpessoais e valores se referem a vidas individuais (JOAS, 2001). Portanto, para Habermas (1997a) as questões de justiça, diferentes das questões de ética (vida boa), devem ser vistas como princípios que almejam validade geral, além de determinada coletividade. $O$ autor esclarece, todavia, que:

Não vinculamos tal pretensão normativa de validade [universal] a valores culturais; no entanto, os valores pleiteiam a corporificarão em normas; em face de uma matéria que careça de regulamentação, eles podem obter obrigatoriedades gerais. À luz de valores culturais, as carências de um indivíduo revelam-se plausíveis também para outros indivíduos situados na mesma tradição [...]. Neste caso, os envolvidos podem esperar uns dos outros que cada um deles, em situações correspondentes, oriente seu agir segundo valores preceituados de maneira normativa para todos os atingidos (HABERMAS, 2012a, p. 171-172).

Putnam (2008), por sua vez, afirma que a objetividade pressuposta para as normas implica objetividade para pelo menos alguns valores e acusa Habermas de um naturalismo e "não cognitivismo" em relação aos valores. Habermas, em réplica, afirma que a tentativa de conciliação de Putnam (2002; 2008) cai em um realismo cognitivo axiológico (LIMA, 2013). Habermas $(2005$, p. 170) coloca que "Putnam afirma uma continuidade entre juízos de fato e juízos de valor". Para Habermas (2005, p. 185), no entanto, "o sentido de validez dos juízos assertórios, que enunciam o que é efetivo, não é o mesmo que o dos juízos morais, que enunciam o que tem valor de obrigação categórica para a ação". Nisso, o autor argumenta que "os juízos morais distinguem-se, comparados aos juízos de valor não morais, pela universalidade de sua pretensão de validez" (HABERMAS, 2005, p. 19). E, assim, os valores possuem um campo de validez diferente.

A posição de Habermas é de um cognitivismo fraco - a objetividade dos valores é vista apenas como intersubjetividade em determinado grupo social (LIMA, 2013; 2014). Por isso, Putnam (2008) afirma que Habermas trata as normas em sentido kantiano, e os valores naturalisticamente - criando uma lacuna entre valores e normas: "Eles [os valores] são vistos como produtos sociais contingentes, que variam conforme variam os diferentes mundos da vida" (PUTNAM, 2008, p. 151). Portanto, para Habermas, segundo Putnam (2008, p. 151), os valores não transcendem "'o mundo da vida' de um grupo particular". A posição de Putnam é: "eu sustento que tais juízos [de valor], na prática, são vistos como verdadeiros ou falsos e assim devem ser vistos" (PUTNAM, 2008, p. 152, grifo do autor).

Nisso, Habermas não considera os valores acessíveis à ética do discurso, pois, "os valores têm a ver com o bom, e não com o justo, com o que cada sociedade considera importante e desejável [...]. A ética do discurso não pode, portanto, nem examinar os valores nem proclamar a universalidade e alguns dentre eles" (ROUANET, 1989, p. 68). No entanto:

A insistência de Habermas em manter a distinção conceitual e formal entre "valores" e "normas" nem sempre é convincente. Enquanto as normas podem e devem ser submetidas a um procedimento discursivo para adquirirem sua validade, os "valores" ficam relegados ao campo do "mundo vivido" e aqui ao subsistema cultural, de onde não têm condições de se desprenderem para fins de uma "validação universal" (FREITAG, 2005, p. 195).

Dessa forma, Habermas não considera devidamente a importância dos valores, mesmo que "em ensaios recentes, [...], embora venha admitindo a pertinência do papel dos valores, Habermas (2001) continua a aprisioná-los nos procedimentos enquanto condições prévias à democracia, conferindo-Ihes um papel secundário no desenho normativo do deliberacionismo" (PERLATTO, 2015, p. 141). Contudo, a posição de Habermas não torna os valores irracionais e ele define-se como um cognitivista, mesmo que seja um cognitivismo fraco (LIMA, 2013; 2014). Seu conceito de racional, de alguma forma, engloba fatos e valores (mesmo que de forma limitada): 
Denominamos racionais os sujeitos capazes de agir e falar que na medida do possível não se enganam quanto a fatos e relações meio fim. Mas é evidente haver também outros tipos de exteriorizações para as quais pode haver boas razões, mesmo que não vinculadas a pretensões de verdade ou êxito. Em contextos de comunicação não chamamos de racional apenas quem faz uma asserção e é capaz de fundamentá-la diante de um crítico, tratando de apresentar as evidências devidas. Também é assim chamado de racional quem segue uma norma vigente e se mostra capaz de justificar seu agir em face de um crítico, tratando de explicar uma situação dada à luz de expectativas comportamentais legítimas. E é chamado de racional até mesmo quem exterioriza de maneira sincera um desejo, um sentimento ou um estado de espírito, quem revela um segredo, admite ter cometido um ato qualquer etc. e então se mostra capaz de dar a um crítico a certeza dessa vivência revelada, tratando de tirar consequências práticas disso e comportar-se a partir dali de maneira consistente (HABERMAS, 2012a, p. 43-44).

Por isso, consoante Rodrigues (2013), Habermas também supera a dicotomia entre fatos e valores, mostrando que sobre ambos pode-se alcançar uma decisão racional. Freitag (1989) destaca que Habermas consegue isso por meio da ação comunicativa. Para a autora, a ação comunicativa permite uma conexão entre as partes (objetiva; social; subjetiva) realizadas por meio da linguagem. Para Rouanet (1989, p. 68), a ética do discurso pode "ir mais longe" e incluir normas e valores. Adiante, segundo Rouanet (1989), os valores poderiam ser discutíveis por vias discursivas (processo de argumentação) sem grandes problemas dentro da abordagem da ética do discurso do próprio Habermas. Como síntese do debate, consideramos que os valores podem ser "objetivos" e os atores podem engajar-se em uma discussão a respeito deles no ambiente avaliativo.

Vale ressaltar, ainda, a aproximação proposta por Serva (1997, p. 120) entre Guerreiro Ramos e Habermas no que se refere a fatos e valores: "a grande importância concedida aos valores é um traço característico e por demais evidentes nas duas propostas. [...], fica evidente que os valores em que se fundam os princípios éticos são parte substancial em ambas as teorias". Assim, Serva (1997, p. 121) considera a questão dos valores e dos fatos em Habermas:

Em Habermas, podemos afirmar, sem sombra de dúvida, que interpretação e valor também são duas esferas circunscritas e a todo o momento presentes na sua formulação. A interpretação das realidades e das emissões comunicativas se dá com base no contexto normativo do mundo-da-vida, em seu conceito cotidiano. Os valores fornecem a medida da interpretação da validade das pretensões dos agentes e condicionam o consenso, delimitando as possibilidades do entendimento. Por ter elaborado uma teoria de ação, Habermas demonstra a mecânica interpretativa dos fatos e das comunicações através de valores (SERVA, 1997, p. 121).

Essas discussões permitem que argumentemos sobre a importância da comunicação e da linguagem (e do mundo-da-vida intimamente relacionado com essas categorias) para a construção dos sentidos e significados da avaliação e da consideração dos valores no processo avaliativo - assim, essa abordagem contribui notadamente para conceber uma dialogicidade entre fatos e valores. Nossa perspectiva valorativo-comunicativa tem como fundamento epistemológico o mundo-da-vida na acepção de Habermas e a relação entre fato e valor em Putnam que permitem, em conjunto, constatar que, na prática cotidiana dos Públicos Constituintes, fatos e valores são interdependentes, inclusive na prática dos próprios avaliadores.

\section{LÓCUS AVALIATIVO, MAPA DE BENS PÚBLICOS E EXPECTATIVAS, NECESSIDADES, CAPACIDADES, INTERESSES E REPRESENTAÇÕES (ENCIRS)}

Argumentamos nesta seção que a comensurabilidade prática dos juízos de fato e valor é realizada pelo processo avaliativo como instrumentos comunicativos. Não existe, assim, prioridade de um juízo sobre outro, mas diferenças e complementaridades na informação que agregam. Esse raciocínio permite, ainda, incorporar a incerteza decorrente da decisão em estados de informação incompleta, nos quais a variedade e variabilidade dos achados avaliativos e de seus possíveis determinantes não são impeditivos da razão, por subjetividade ou probabilidade de ocorrência, mas refletem a articulação imprecisa do mundo prático, da variedade dos indivíduos e de sua ação social que não pode prescindir da ação comunicativa para elaboração de conteúdos significativos (HABERMAS, 2012a; 2012b). É para essa explicita tarefa que concorrem o Mapa de Bens Públicos e 
o Mapa Semântico de ENCIR, como instrumentos avaliativos e ferramentas de auxílio do processo dialógico de tradução nos mundos-da-vida dos significados dos experimentos sociais de avaliação.

Nos processos avaliativos é importante, assim, que a construção das formas de avaliação tenha reconhecimento intersubjetivo, para que possa explicitar da maneira mais próxima possível os mundos-da-vida dos Públicos Constituintes e os impactos dos projetos, ações e práticas sobre eles. Esses princípios eliminam a possibilidade de criação de uma forma de avaliação padrão (conjunto de indicadores), pois exigem, mediante os princípios da discussão, que não sejam replicáveis no processo de captar as especificidades tanto dos bens produzidos como dos valores reproduzidos (indicamos na seção anterior alguns que podem ser considerados importantes a priori). O que organizamos são os procedimentos sistemáticos, as formas de organizar essas demandas, o que pode ocorrer por meio do Mapa de Bens Públicos e do Mapa Semântico de ENCIR, isto é, a perspectiva valorativo-comunicativa. É importante destacar que o que fica são procedimentos, pois, para Habermas "a ética discursiva não pode postular a validade universal de normas materiais, mas apenas propor um procedimento para a validação dessas normas" (ROUANET, 1989, p. 68) - raciocínio este que consideramos relevante para nossa proposta. Além disso, para Habermas, os filósofos, e, para nós, os avaliadores não podem gerar normas ou valores (em sentido top-down), dado que devem contar com a participação dos envolvidos, no nosso caso dos Públicos Constituintes. Nisso, deve ficar claro que o Mapa de Bens Públicos e o Mapa Semântico de ENCIR não são instrumentos que servem para estabelecer fatos e valores a priori - a lista de valores públicos dentro de um Estado Democrático de Direito serve apenas como direcionamento ou referência de uma possível pesquisa empírica.

O ponto de partida para a elaboração do Mapa Semântico de ENCIR (MSE) é o exame do Mapa de Bens Públicos (MBP) desenvolvido por Cabral (2011), para onde remetemos o leitor. O MBP faz parte da metodologia de avaliação aplicada a projetos sociais e práticas de organizações de interesse público. Trata-se de um inventário dos bens e valores desenvolvidos, articulados de acordo com sua relação normativa, de modo a captar os bens públicos produzidos e os valores reproduzidos de acordo com sua concepção do processo original de gestão.

Tomado como um desenho de avaliação (Quadro 3), o MBP é construído para afastar a alegada intangibilidade de benefícios na forma de valores reproduzidos pelas ações e práticas sociais. Encontra justificativa na relevância dos valores no processo comunicativo dos atores sociais e lembrando a organização do modelo lógico (FERREIRA, CASSIOLATO e GONZALEZ, 2007) enquanto ferramenta. Entretanto, o MBP se diferencia desse modelo por suspender juízos causais e de finalidade e fixar-se na explicitação dos valores, como juízo relevante para apontar os vínculos com os resultados. Vale insistir na superação do raciocínio causal e finalista para afastar a redução do processo avaliativo a um esquema de pareamento de meios e fins e garantir a explicitação dos valores como elementos de vinculação dos fatos avaliativos. Como resultado prático, o MBP oferece, principalmente, a identificação nesta ordem: do objeto de avaliação representado na coluna "benefício" e lido como o impacto mensurável; dos "bens públicos" desenvolvidos e expressos como "fatos e valores"; e dos "resultados" esperados que se apresentam como os "indicadores" (qualitativos e/ou quantitativos) do processo avaliativo em foco. Essa interpretação articulada do processo de gestão, para efeito avaliativo, constitui-se no espaço avaliativo ou no desenho do processo que identifica, sob a vinculação dos valores e fatos, os elementos fundamentais para o desenvolvimento da avaliação. Portanto, nessa construção devem participar todos os Públicos Constituintes e os avaliadores. Esse mapa proporciona uma síntese dos debates e das interpretações que emergem dos mundos-da-vida dos Públicos Constituintes.

\section{Quadro 3}

\section{Mapa de Bens Públicos}

\begin{tabular}{|c|c|c|c|c|c|c|c|c|}
\hline Recursos & Atividades & Focos & Projetos & Bens públicos & Beneficiário & Resultados & Capacidades & Benefício \\
\hline Custos sociais & Intervenções & Temas & Ações & Fatos e valores & Foco do impacto & Indicadores & Dimensões & Impacto \\
\hline
\end{tabular}

Fonte: Elaborado pelos autores.

A avaliação consiste, em sequência, na identificação do processo comunicativo entre os Públicos Constituintes estabelecidos no ambiente institucional, de modo a sugerir a construção de instrumentos para coletar as informações necessárias à explicitação dos valores e fatos em tela. É bom lembrar que essa proposta ressalta a construção do espaço de avaliação, isto é, os instrumentos e indicadores são construídos para o caso, pois, como também destacam Boullosa e Rodrigues (2014, p. 151), 
"se cada avaliação possui sua própria lógica e pesquisa avaliativa, não é possível imaginar que exista uma receita comum". House e Rowe (2000) destacam, ainda, o caráter de unicidade de cada caso a ser avaliado.

O desenho desse processo comunicativo entre os Públicos Constituintes pode ser expresso em outro instrumento, que Cabral e Muzy (2014) denominaram MSE e que apresentamos no Quadro 4 para exemplificar o processo de tradução de significados que se reconhece na avaliação. Destacamos que o MSE consiste no arranjo para cada Público Constituinte dos conteúdos significativos de suas respectivas "expectativas", "necessidades", "capacidades", "interesses" e "representações".

\section{Quadro 4}

Processo de elaboração do Mapa Semântico de ENCIR

\begin{tabular}{|c|c|c|c|c|c|}
\hline \multirow{2}{*}{ ENCIR } & \multicolumn{5}{|c|}{ Fatos/valores } \\
\hline & Expectativas & Necessidades & Capacidades & Interesses & Representações \\
\hline Significado & Visão do futuro & $\begin{array}{l}\text { Função do que } \\
\text { faz ou recebe }\end{array}$ & $\begin{array}{c}\text { O que sabe e tem } \\
\text { liberdade de fazer } \\
\text { ou receber }\end{array}$ & $\begin{array}{c}\text { O que o leva a } \\
\text { fazer } \\
\text { ou receber }\end{array}$ & O que simboliza \\
\hline Questões/linguagem & Qual? & Como? & Quanto? & Por quê? & O quê? \\
\hline Modo de fruição & Mediato & Imediato & Bem mensurável & Instrumentos & Símbolos \\
\hline
\end{tabular}

Fonte: Elaborada pelos autores.

Na segunda linha do MSE lemos os significados de ENCIR, ou as expressões que denotam o que os Públicos Constituintes reconhecem como significado de suas expectativas, necessidades, capacidades, interesses e representações que assumem em seus discursos acerca dos bens públicos por eles fruídos. Dessa forma, dependendo de crenças, valores e costumes vivenciados pelo ser no mundo. A terceira linha apresenta as perguntas originais de investigação que permitem identificar esses significados no processo prático da avaliação. Assim, por exemplo, para identificar as expectativas do indivíduo com a fruição do bem, indica-se a pergunta "qual é a sua visão de futuro?", decorrente de sua vinculação ao projeto/ação social avaliado(a). As perguntas são factíveis porque representam os elementos comunicativos elaborados pelos públicos para o estabelecimento de seu agir nesse espaço.

Na quarta linha, apresenta-se a natureza dos bens fruídos ou os modos de fruição dos bens. As expectativas são mediatizadas pelo processo de participação/comunicação, enquanto as necessidades mostram-se imediatas na fruição do bem público. Os interesses expressam modos instrumentais de abordagem do bem, enquanto as representações expressam a simbologia inerente à sua significação. As capacidades, cuja centralidade no Quadro 4 nos remete às considerações de Sen (2000), acerca das liberdades de acesso e fruição, manifestam-se como os atributos mensuráveis no processo avaliativo. No final, será possível constatar, por meio da expressão de fatos e valores, diversas expectativas (como: crescimento da empresa, trabalho, renda, desenvolvimento local, proteção, redução de risco etc.), necessidades (como: atingir resultados, participar, remuneração, apoio etc.), capacidades (como: tempo, dedicação etc.), interesses (como: resultado econômico, assistência, redução de risco, realização pessoal, compartilhar valores etc.) e representações (como: cooperação, progresso social, coesão etc.).

Esses processos também abrem espaço para a análise dos critérios apresentados por Tenório, Villela, Dias et al. (2008) e Tenório, Dias, Villela et al. (2010) sendo interpretados para cada conjunto de Públicos Constituintes, isto é, qual é o(a) ENCIR dos Públicos Constituintes acerca dos processos de discussão, inclusão, pluralismo, igualdade participativa, autonomia e bem comum. Dessa forma, como sugere Tenório $(2013$, p. 8) no âmbito da gestão social:

[...] é necessário que o processo ocorra de maneira dialógica, intersubjetiva, isto é, a troca de interpretações da realidade entre os concernidos à situação-problema (cidadãos, agentes públicos, agentes econômicos, agentes sociais etc.) deve acontecer de modo a que todos tenham direito a expor suas razões.

Ainda, na gestão social enquanto campo que possibilita esse diálogo com o interesse público é relevante a tomada de decisão coletiva sem coerção, dialogicidade e a autonomia dos públicos (CANÇADO, PEREIRA e TENÓRIO, 2013). 
Finalmente, o MSE apresenta o processo de comunicação entre os públicos da mesma forma que o MBP apresenta o processo de gestão. Daí decorre a justaposição do agir comunicativo e do processo de gestão vinculados pelos valores como elementos simbólicos. Esse processo descreve a experiência avaliativa como o conceito de mundo-da-vida e a superação da dicotomia fato $x$ valor podem contribuir para esclarecer o processo de avaliação em gestão social, garantindo a consideração dos valores como elementos dotados de racionalidade. Para tanto, o mundo-da-vida como o campo da própria intuição, ou um espaço de "evidências originárias", para o qual o cientista se volta para verificar a validade das teorias, é ainda o lócus onde os indivíduos realizam o entendimento sobre as outras esferas do sistema social por meio do processo comunicativo.

A Figura 1 foi desenvolvida como síntese do ambiente avaliativo. No centro, o Mapa de Bens Públicos organiza os significados atribuídos pelos Públicos Constituintes (ampliados para diversas possibilidades: gestores públicos, ativistas, conselheiros, beneficiários, voluntários, funcionários, instituidores, empresários e implementadores - em cada caso, haverá determinados públicos que não necessariamente serão estes) que são captados por ENCIRs. Também destacamos os diversos valores públicos de forma ilustrativa (na figura as dimensões do desenho não possuem relações empíricas). Em especial, os critérios/ valores não possuem posição fixa e, dessa forma, flutuam em um espaço tridimensional. Adiante, como afirmado, tratamos do processo avaliativo em um lócus, espaço ou esfera da intersecção do Estado, mercado e sociedade/comunidade e, assim, também é um espaço de influências e tensões entre o mundo-da-vida e o sistema (representados pelas setas na cor cinza; colonização, influência e resistência do/no espaço compartilhado) ou cruzamento, conforme coloca Vandenberghe (2014). Consoante Alcântara (2015), esse é um lócus que deve ser explorado empiricamente e teoricamente pela gestão social.

\section{Figura 1}

\section{Perspectiva valorativo-comunicativa - MBP e ENCIR}

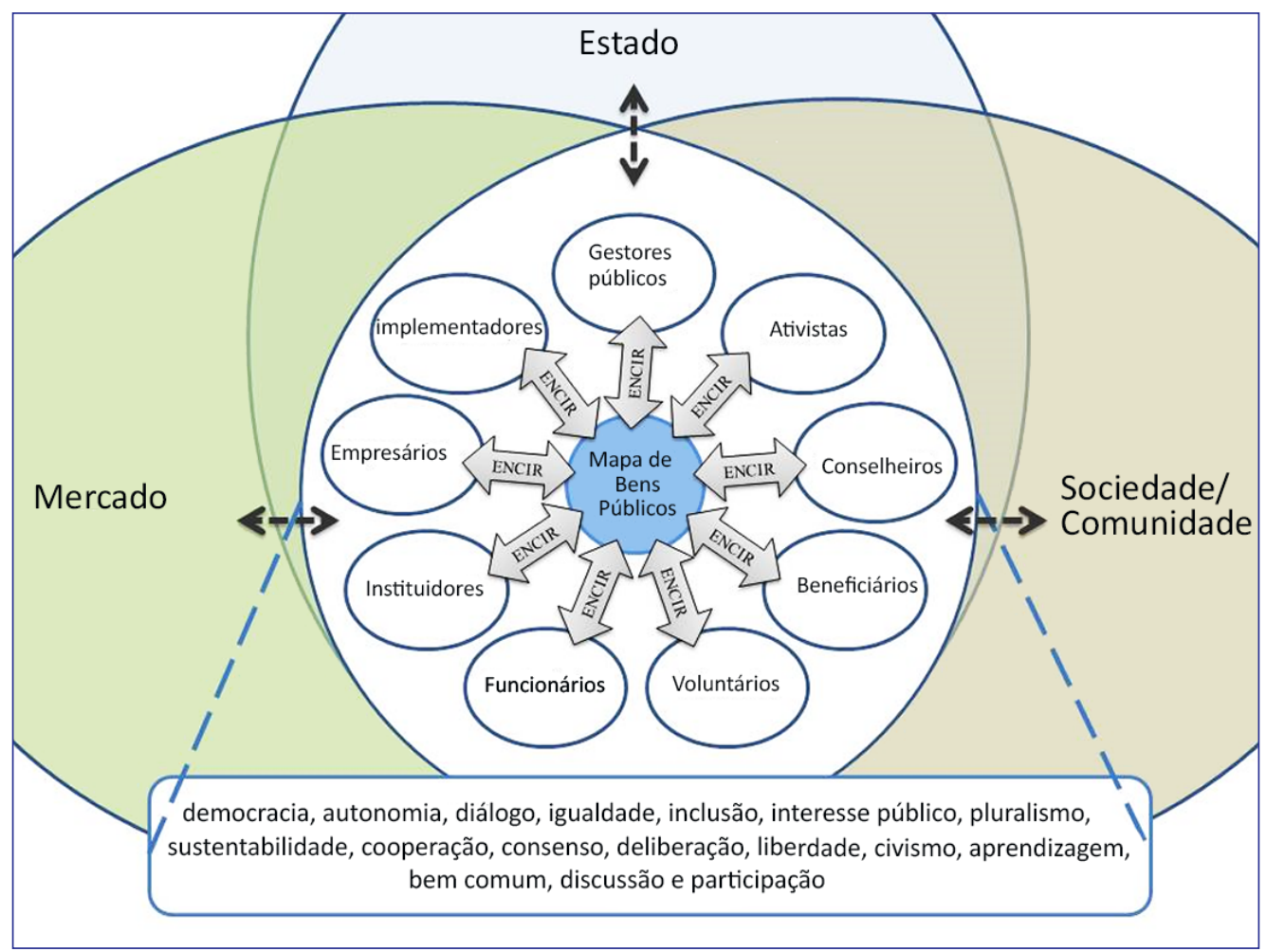

Fonte: Elaborada pelos autores.

Concomitantemente, a avaliação aqui apresentada consiste, em sequência, na identificação do processo comunicativo entre diversos atores sociais estabelecido no ambiente avaliativo, de modo a sugerir a construção de instrumentos, processos e técnicas para coletar as informações necessárias à explicitação dos valores e fatos, bem como a consideração das demandas/ 
tensões tanto do mundo-da-vida quanto do sistema - relações, tensões, momentos cooperativos e conflitivos que, segundo Alcântara (2015), devem ser explorados pelo campo de estudos da gestão social.

De fato, além disso, é preciso considerar que existem entre os atores envolvidos (diversos Públicos Constituintes) assimetrias inevitáveis, especialmente, "no tocante às informações" (HABERMAS, 1997b, p. 54) que o Mapa de ENCIR e o Mapa de Bens Públicos ajudam a identificar e explicar. Habermas (1997b, p. 54) considera que

[...] as fontes da participação em comunicações políticas são geralmente escassas, ou seja: o tempo do qual cada indivíduo dispõe é exíguo; a atenção prestada aos temas, que têm a sua própria história, é episódica; a disposição e a capacidade de dar contribuições próprias para esses temas é pouca.

Além disso, os atores estão envolvidos em estruturas sociopolíticas que não podem ser ignoradas pelos avaliadores - estas devem ser consideradas nos casos empíricos em estudo. O que o processo avaliativo busca é criar um ambiente em que essas condições possam ser objeto de crítica por parte dos próprios participantes do processo e, nesse sentido, visa a permitir que os Públicos Constituintes tenham direito à palavra - nos termos de Habermas (1997a), que tenham liberdade comunicativa de dizer sim ou não diante das pretensões de validade levantadas no processo. E, segundo Habermas (1997b), mesmo sendo um caminho difícil, ele é necessário para um processo legítimo e democrático de formação da vontade pública e de decisões políticas.

A ilustração também nos permite discutir a "colonização do mundo-da-vida" (HABERMAS, 2012b). Essa colonização (a burocratização pode ser entendida como uma de suas possibilidades; avaliações tecnocráticas, centralizadoras e hierárquicas; exigências imperativas de produtividade/desempenho e outras) impõe restrições à importância dos processos comunicativos entre os diversos atores sociais, criando, assim, diversas tensões. Essas tensões podem variar de acordo com os Públicos Constituintes e os objetivos da avaliação em foco.

Neste espaço público [área em branco na Figura 1], reconhecemos o campo de tensões estruturais onde se debatem as relações, os interesses e as necessidades, as expectativas dos indivíduos que atuam publicamente. Estas tensões se manifestam principalmente nas relações entre o mercantil e a esfera pública; entre o mundo uniforme das organizações com discursos e finalidades dirigidas e o mundo plural e inespecífico abordado pela comunidade; entre o mundo formal das organizações estruturadas e a informalidade comunicada pela comunidade e seus valores (CABRAL, 2008, p. 25).

É exatamente para evitar as "patologias" decorrentes da colonização que destacamos a importância dos valores públicos (e, aqui, também dos valores republicanos) e sua reprodução (democracia, autonomia, diálogo, igualdade, inclusão, interesse público, pluralismo, sustentabilidade, cooperação, consenso, deliberação, liberdade, civismo, aprendizagem, bem comum, discussão e participação). Logo, consideramos que os valores são representações dos mundos-da-vida e representam, ainda, como eles "podem ser", servindo como norte das práticas sociais.

Outra faceta da colonização pode ser pensada em relação à própria ciência avaliativa. Se pensarmos com Husserl (2002) e Habermas (2012b), é possível observar que os processos avaliativos que se prendem apenas em fatos pelo viés dos positivistas lógicos distanciam-se do mundo-da-vida, afinal, "o racionalismo ocidental orienta-se, única e exclusivamente, pela esfera dos fatos" (PIZZI, 2006, p. 82-83). Outros autores também corroboram esse diagnóstico, como os próprios Habermas (2012a) e Guerreiro Ramos (1981). Lancey (2006, p. 261-262) narra como a visão voltada apenas para os fatos em detrimento dos valores se tornou dominante:

[...] abordagem da pesquisa científica, que se volta apenas para os fatos brutos, atingiu hegemonia quase total na ciência moderna, por causa das suas vinculações dialéticas com a sustentação de alto valor ético a um conjunto de valores - que chamo "a valorização moderna do controle" - que inclui o valor de aumentar a capacidade humana para controlar objetos naturais, bem como o exercício desta capacidade sempre em mais domínios da vida.

Assim, comumente o mundo-da-vida é solapado das experiências avaliativas que se focam nos fatos. De outra forma, a avaliação proposta valora a incerteza em detrimento do controle (CABRAL e MUZY, 2014). Essa pode ser a saída para o medo 
habermasiano do imperialismo cultural da universalidade de determinados valores, isto é, não abandonar a discussão racional dos valores, tão apenas, como indicou Putnam (2008, p. 66, grifo do autor) na direção de John Dewey: "investigar, discutir e tentar coisas cooperativa, democrática e, acima de tudo, falibilisticamente" - isto é, sempre abertas a críticas. Portanto, para Putnam (2008, p. 177), "aceitar que valores éticos podem ser discutidos racionalmente e que eles não precisam ser 'naturalizados' não é a mesma coisa que aceitar o apriorismo ou o autoritarismo com relação aos valores".

A eliminação dos juízos de valor é uma forma de transformar os processos avaliativos em atividades que passam a ser coordenadas por outros meios que não os linguísticos, simbólicos, valorativos e comunicativos - retirando também, como alertou Guerreiro Ramos (1981), os aspectos éticos e, consequentemente, "do ponto de vista da filosofia de Hume [dicotomia fato $x$ valor], estaríamos fadados a ter que manter enunciados éticos separados dos enunciados de fato" (MELLO JUNIOR, 2014, p. 8). Assim, procuramos demonstrar que "o ato de valoração [atribuir valor] - que é feito por um sujeito que não pode deixar de valorar, pois, valorar é existir - é, por um lado, subjetivo e relacional e, por outro lado, objetivo e material" (PEDRO, 2014, p. 491). E, ainda, concordamos com Tenório $(1998$, p. 10) no sentido de que "manter o dualismo formalista de fatos e valores que as teorias tradicionais realçam significa atuar a serviço do status quo".

Dessa forma, buscamos fugir de soluções tipicamente técnicas (no sentido reducionista), pois, quando "a solução de tarefas técnicas não está referida à discussão pública", exclui a participação da população levando à despolitização (HABERMAS, 1987, p. 71). Em contrapartida, temos a ação comunicativa (e a ética da discussão), que permite uma revisão dessas questões e suas adequações a um contexto democrático.

Nesse sentido, também vale lembrar que, tanto para Schütz (1979) quanto para Habermas (2012b), o mundo-da-vida se relaciona com o conhecimento acumulado por meio de experiências. Portanto, o conhecimento avaliativo pode ser construído durante todo o processo. Isso diferencia essa perspectiva de um modelo padronizado/linear de aplicação de instrumentos genéricos ou a contagem dos fatos, como número de envolvidos, total de investimento e uso dos recursos - a contagem de fatos é apenas uma dimensão ou face dos processos avaliativos. Paes de Paula (2013, p. 527) apresenta essa discussão de forma mais ampla:

As críticas da ciência e da cultura habermasiana e frankfurtiana então se articulam: a práxis se anula diante do comportamento condicionado e é absorvida pela techné. A consciência tecnocrática exclui do horizonte social as questões práticas (comunicativas) e o positivismo exclui do horizonte cognitivo as normas e valores, uma vez que as proposições descritivas são empiricamente controláveis, enquanto as proposições normativas, não. As proposições normativas foram condenadas à inverificabilidade e à contingência da mera opinião, mas a teoria da ação comunicativa veio para tentar corrigir isso.

Finalmente, a dicotomia fato $x$ valor pactua com uma cegueira cognitiva (PAES DE PAULA, 2014) e também reflete a separação dos conhecimentos teórico, prático e emancipatório - dessa forma, as análises e os processos avaliativos se tornam unidimensionais, parciais e seguem uma lógica, voltada apenas aos fatos e ao conhecimento que possa gerar "resultados" (em termos da lógica da ação estratégica) - especialmente nas mãos de avaliadores tecnocratas. As avaliações tradicionais positivistas, focadas em fatos, colocam os valores como apenas resíduos que devem ser minimizados. A busca que fazemos é por trazer de volta essa dimensão esquecida do mundo-da-vida, a partir do qual não abrimos mãos dos fatos nem dos valores, mas apenas reconstruímos nossas relações com eles de forma mais comunicativa e simbólica, isto é, como certamente asseguram Jürgen Habermas e Hilary Putnam, mais humana.

\section{CONSIDERAÇÕES FINAIS}

Argumentamos neste artigo que o processo avaliativo (na perspectiva valorativo-comunicativa da avaliação) é revelador de valores e fatos quando orientado pelo entendimento e pela compreensão dos signos e não somente pela finalidade instrumental da decisão. Nesse sentido, a experiência avaliativa é esclarecimento e não estabelecimento estratégico de causas teleológicas. Encontramo-nos com o raciocínio de Jürgen Habermas que reconhece o desenvolvimento da linguagem e a orientação comunicativa da ação e que os processos instrumentais/estratégicos e comunicativos ocorrem em momentos epistemológicos diversos, além disso, a reflexão instrumental é tardia em relação ao desenvolvimento da linguagem. 
Essas considerações aplicadas ao experimento avaliativo permitem estabelecer a base epistemológica e o percurso lógico de conhecer os valores no campo do espectro das possibilidades do fenômeno avaliado (CABRAL e MUZY, 2014), sem individualizar causas como fatores teleológicos específicos e abstratos. Nesse mesmo sentido, apresentamos uma importante característica da prática/teoria da avaliação, que é o foco na participação dos interessados.

As discussões enfocaram as contribuições dos filósofos Hilary Putnam (fato e valor) e Jürgen Habermas (mundo-da-vida) e também de avaliadores como Ernest R. House e Kenneth R. Howe. Concluímos, provisoriamente, que o conceito de mundo-da-vida e a refutação da dicotomia fato $x$ valor são fundamentos epistemológicos coerentes dos processos e instrumentos da avaliação que considera os valores e bens do espaço público no âmbito da proposta da gestão social. Neste artigo, abordamos como esses conceitos são férteis (complementarmente) em análises sociais e especialmente no âmbito da gestão social como uma possível chave de leitura para compreender e construir possibilidades de avaliação. Argumentamos que no processo avaliativo ocorre uma interação entre os avaliadores e os diversos Públicos Constituintes, e que essa interação, normativamente, deve ser balizada pela linguagem como forma de entendimento e acordo, onde as interpretações podem emergir de saberes implícitos compartilhados pelos participantes da interação.

A comunicação deve ser a base da criação de processos e instrumentos de avaliação - uma visão intersubjetiva na qual a relação ocorre entre sujeitos, seus fatos (bens e serviços) e valores produzidos e reproduzidos. Portanto, os processos de avaliação devem considerar os mundos-da-vida como parte essencial da construção de um conhecimento válido sobre o impacto dos projetos, ações e práticas sociais. É bom que se esclareça, ainda, que a volta ao mundo-da-vida não significa abandonar a objetividade dos fatos em direção aos valores, mas apenas considerar que ambos fazem parte da construção social e dos processos avaliativos.

De modo coerente com a existência dos mundos-da-vida dos diversos Públicos Constituintes, ressaltamos que o espaço da avaliação é construído para o caso a ser avaliado e, com isso, não é possível estabelecer uma generalização $a$ priori - ela está condicionada aos processos comunicativos e à aceitação por parte dos envolvidos. A pluralidade que nos revela o Mapa Semântico de ENCIR deve ser tomada como passo importante e não limada ao processo de forma monológica. Assim, os indicadores de avaliação devem ser construídos com todos os Públicos Constituintes e, por isso, não são dados a priori - são coproduzidos por meio da inclusão, do diálogo e da deliberação. E, nesse sentido, são validados intersubjetivamente, atendendo às pretensões de validade habermasiana de verdade, sinceridade e correção normativa - considerando, ao mesmo tempo, suas capacidades nos termos de Amartya Sen. O que apresentamos como procedimentos sistemáticos são os processos, os valores democráticos e as formas de organizar essas demandas, que podem ocorrer por meio do Mapa de Bens Públicos e do Mapa Semântico de ENCIR, ou seja, a perspectiva valorativo-comunicativa.

Como adendo, destacamos que os pragmatistas, como Hilary Putnam, Donald Davidson, John Dewey e Richard Rorty sempre procuraram negar uma distinção rígida entre fatos e valores. Essa distinção, por outro lado, constitui-se de elemento central do positivismo: fatos são objetivos e valores são não objetivos (PUTNAM, 2008). Adiante, para negar essa dicotomia, existem duas saídas: i) a primeira é que não existe objetividade nem de valores nem de fatos; ii) a segunda é que tanto fatos quanto valores podem ser objetivos (GHIRALDELLI JR., 2010). Este artigo argumentou sobre o segundo ponto, onde se destaca que a objetividade não está nas coisas/nos objetos, mas se relaciona com sua produção pela linguagem, pela construção do consenso e pela intersubjetividade.

Uma das limitações desta pesquisa foi a abordagem resumida das discordâncias entre Jürgen Habermas e Hilary Putnam acerca das especificidades com que tratam fatos, valores e normas (não foram discutidos o texto de Putnam, Antwort auf Jürgen Habermas, de 2002, e uma ampla literatura pragmatista e crítica, principalmente norte-americana e alemã sobre a questão dos valores e das normas) - esses textos podem direcionar novas pesquisas. Ademais, aproximar esse debate de autores mais próximos aos estudos das organizações, como Herbert Simon, a partir de leituras como a de Oliveira e Paes de Paula (2014). Por fim, destacamos como limitação a falta de um debate mais aprofundado da questão do conflito entre valores e de como o processo avaliativo é um processo político. Sugerimos que essas limitações e sugestões sejam foco de futuros trabalhos, tanto teóricos quanto empíricos. 
Fatos, valores e o mundo-da-vida: argumentos epistemológicos para avaliação no âmbito da gestão social
Valderí de Castro Alcântara | Eloísa Helena de Souza Cabral Paulo de Tarso Muzy | José Roberto Pereira

\section{REFERÊNCIAS}

ALCÂNTARA, V. C. Mundo-da-vida e sistema: o lócus da gestão social sob a abordagem habermasiana. Dissertação (Mestrado em Administração) - Universidade Federal de Lavras, Lavras, 2015.

ALLEBRANDT, S. L. et al. Gestão social e cidadania deliberativa: uma análise da experiência dos Coredes no Rio Grande do Sul, 1990-2010. Cad. EBAPE.BR, v. 9, p. 914-945, 2011.

ANDERSEN, L. B. et al. Public values and public service motivation: conceptual and empirical relationships. American Review of Public Administration, v. 20, n. 10, p. 1-20, 2012.

ANDREWS, C. W. Emancipação e legitimidade: uma introdução à obra de Jürgen Habermas. São Paulo: Ed. Unifesp, 2011.

BOULLOSA, R. F.; RODRIGUES, R. W. S. Avaliação e monitoramento em gestão social: notas introdutórias. Revista Interdisciplinar de Gestão Social, v. 3, n. 3, p. 145-178, 2014.

BOZEMAN, B. Public values and public interest: counterbalancing economic individualism. Washington, D.C.: Georgetown University Press, 2007.

CABRAL, E. H. S. Espaço público e controle para a gestão social no Terceiro Setor. Serviço Social e Sociedade, v. 86, p. 30-55, 2006.

CABRAL, E. H. S. A gestão social do terceiro setor e suas dualidades. Administração em Diálogo, v. 11, n. 2, p. 21-34, 2008.

CABRAL, E. H. S. Valores e espaço público: referenciais e instrumentos para a avaliação de projetos sociais. Revista de Administração Pública, v. 45, p. 1915-1941, 2011.

CABRAL, E. H. S.; MUZY, P. T. Os valores e o valor da moeda: hipóteses sobre a comensurabilidade e a monetarização do impacto de projetos sociais. Cad. EBAPE.BR, v. 12, p. 339-356, 2014.

CANÇADO, A. C.; PEREIRA, J. R.; TENÓRIO, F. G. Gestão social: epistemologia de um paradigma. Curitiba: CRV, 2013.

CASTELLÀ, C.; PARÉS, M. Participação e qualidade democrática: uma proposta de critérios de qualidade. In: TENÓRIO, F. G. (Org.). Cidadania e desenvolvimento local: critérios e análise. Rio de Janeiro: Ed. FGV, 2012. 207-251 p.

COHEN, J.; ARATO, A. Civil society and political theory. Cambridge, MA: The MIT Press, 1992.

COSTA, S. Esfera pública, sociedade civil e movimentos sociais no Brasil. Novos Estudos CEBRAP, n. 38, p. 38-52, 1994.

DIAS, A. F. Região do Coredes Noroeste Colonial e Caleiro (RS). In: TENÓRIO, F. G. (Org.). Cidadania e desenvolvimento local: critérios e análise. Rio de Janeiro: Ed. FGV, 2012. 159-180 p.

DIAS SOBRINHO, J. Avaliação educativa: produção de sentidos com valor de formação. Avaliação, v. 13, n. 1, p. 193-207, 2008.

DOMINGUES, J. M. Criatividade social, subjetividade coletiva e a modernidade brasileira contemporânea. Rio de Janeiro: Contra Capa, 1999.

FARIA, C. A. P. A política da avaliação de políticas públicas. Revista Brasileira de Ciências Sociais, v. 20, n. 59, p. 97-110, 2005.
FERREIRA, H.; CASSIOLATO, M.; GONZALEZ, R. Como elaborar modelo lógico de programa: um roteiro básico. 2007. Disponível em: <http:// agencia.ipea.gov.br/images/stories/PDFs/TDs/td_1369.pdf >. Acesso em: 6 jan. 2015.

FREITAG, B. A questão da moralidade: da razão prática de Kant à ética discursiva de Habermas. Tempo Social, v. 1, n. 1, p. 7-44, 1989.

FREITAG, B. Dialogando com Jürgen Habermas. Rio de Janeiro: Tempo Brasileiro, 2005.

GAULEJAC, V. Gestão como doença social: ideologia, poder gerencialista e fragmentação social. São Paulo: Ideias \& Letras, 2007.

GHIRALDELLI JR., P. Donald Davidson e a objetividade dos valores. Redescrições, Edição especial, p. 21-28, 2010.

GREENE, J. Evaluation, democracy, and social change. In: SHAW, I. F.; GREENE, J. C.; MARK, M. M. The SAGE handbook of evaluation. Thousand Oaks, CA: SAGE, 2006. 118-140 p.

GUERREIRO RAMOS, A. A nova ciência das organizações: uma reconceituação da Riqueza das Nações. Rio de Janeiro: Ed. FGV, 1981.

HABERMAS, J. Técnica e ciência como “ideologia”. Lisboa: Ed. 70, 1987.

HABERMAS, J. Consciência moral e agir comunicativo. Rio de Janeiro: Tempo Brasileiro, 1989.

HABERMAS, J. Pensamento pós-metafísico: estudos filosóficos. Rio de Janeiro: Tempo Brasileiro, 1990.

HABERMAS, J. Textos y contextos. Barcelona: Ariel, 1996.

HABERMAS, J. Direito e democracia: entre facticidade e validade. Rio de Janeiro: Tempo Brasileiro, 1997a. v. 1.

HABERMAS, J. Direito e democracia: entre facticidade e validade. Rio de Janeiro: Tempo Brasileiro, 1997b. v. 2.

HABERMAS, J. O discurso filosófico da modernidade. São Paulo: Martins Fontes, 2000.

HABERMAS, J. A constelação pós-nacional: ensaios políticos. São Paulo: Littera Mundi, 2001.

HABERMAS, J. Racionalidade e comunicação. Lisboa: Ed. 70, 2002.

HABERMAS, J. Verdade e justificação: ensaios filosóficos. São Paulo: Loyola, 2004.

HABERMAS, J. Valores e normas: sobre o pragmatismo kantiano de Hilary Putnam. In: ROCHLITZ, R. Habermas: o uso público da razão. Rio de Janeiro: Tempo Brasileiro, 2005. 169-200 p.

HABERMAS, J. A ética da discussão e a questão da verdade. 2. ed. São Paulo: Martins Fontes, 2007.

HABERMAS, J. Comunicação política na sociedade mediática: o impacto da teoria normativa na pesquisa empírica. Líbero, v. 11, n. 21, p. 9-21, 2008.

HABERMAS, J. Teoria do agir comunicativo: racionalidade da ação e racionalização social. São Paulo: Martins Fontes, 2012a.

HABERMAS, J. Teoria do agir comunicativo: sobre a crítica da razão funcionalista. São Paulo: Martins Fontes, 2012b. 
Fatos, valores e o mundo-da-vida: argumentos epistemológicos para avaliação no âmbito da gestão social
Valderí de Castro Alcântara | Eloísa Helena de Souza Cabral Paulo de Tarso Muzy | José Roberto Pereira
HERDY, R. O pragmatismo metodológico: a comunidade da comunicação como limite da agência. Direito, Estado e Sociedade, v. 28, p. 47-58, 2006.

HOUSE, E. R. Unfinished business: causes and values. American Journal of Evaluation, v. 22, n. 3, p. 309-315, 2001.

HOUSE, E. R.; HOWE, K. R. Deliberative democratic evaluation. New Directions for Evaluation, n. 85, p. 1-12, 2000.

HOUSE, E. R.; HOWE, K. R. Valores en evaluación e investigación social. Madrid: Morata, 2001.

HOWE, K. R. Closing methodological divides: toward democratic educational research. Boston, MA: Kluwer Academic, 2002.

HOWE, K. R.; ASHCRAFT, C. Deliberative democratic evaluation: successes and limitations of an evaluation of school choice. Teachers College Record, v. 107, n. 10, p. 2274-2297, 2005.

HUSSERL, E. A crise da humanidade europeia e a filosofia. 2. ed. Porto Alegre: Ed. PUCRS, 2002.

JOAS, H. Values versus norms: a pragmatist account of moral objectivity. The Hedgehog Review, v. 3, n. 3, p. 42-56, 2001.

JØRGENSEN, T. B.; BOZEMAN, B. Public values: an inventory. Administration and Society, n. 39, p. 354-379, 2007.

KEMMIS, S.; MCTAGGART, R. Participatory action research. In: DENZIN, N. K.; LINCOLN, Y. S. (Ed.). Handbook of qualitative research. Thousand Oaks, CA: Sage, 2000. 567-605 p.

LACEY, H. Relações entre fatos e valores. Cadernos de Ciências Humanas, v. 9, n. 2, p. 251-266, 2006.

LIMA, E. C. Realismo cognitivo, naturalismo e pragmatismo ético: a estrutura normativa das 'formas de vida' segundo Habermas e Putnam. Principia, v. 17, n. 3, p. 459-488, 2013.

LIMA, E. C. Notas sobre o debate entre Putnam e Habermas em torno da objetividade dos valores: normatividade, realismo e pragmatismo. Revista Eletrônica de Filosofia, v. 11, n. 2, p. 201-227, 2014.

LUBENOW, J. A. O que há de político na Teoria da Ação Comunicativa? Sobre o déficit de institucionalização em Jürgen Habermas. Revista Philósophos, v. 18, p. 157-190, 2013.

MARICONDA, P. R. O controle da natureza e as origens da dicotomia entre fato e valor. Scientiae Studia, v. 4, n. 3, p. 453-472, 2006.

MARK, M. M. Evaluation's future: furor, futile, or fertile? American Journal of Evaluation, v. 22, n. 3, p. 457-479, 2001.

MARTINO, L. M. S.; MARQUES, A. C. S. Modalidades e derivações da comunicação no mundo da vida: sentidos, experiência e interação. In: ENCONTRO ANUAL DA COMPÓS, 22.; 2013, Salvador. Anais... Salvador: [s.n], 2013. v. 1, p. 1-15.

MELLO JUNIOR, A. F. Do não cognitivismo ao cognitivismo dos enunciados éticos: a mudança nas noções de fato e de objetividade em Hilary Putnam. Revista Redescrições, v. 5, n. 3, p. 1-28, 2014.

NIEMI, H.; KEMMIS, S. Communicative evaluation. Lifelong Learning in Europe, n. 4, p. 5-64, 1999.

NOBRE, M. A teoria crítica. 3. ed. Rio de Janeiro: Zahar, 2011.

OLIVEIRA, L. A.; AYRES, J. R. C. M.; ZOBOLI, E. L. C. P. Conflitos morais e atenção à saúde em aids: aportes conceituais para uma ética discursiva do cuidado. Interface: Comunicação, Saúde, Educação, v. 15, n. 37, p. 363-375, 2011.

OLIVEIRA, K. P.; PAES DE PAULA, A. P. Herbert Simon e os limites do critério de eficiência na nova administração pública. Cadernos Gestão Pública e Cidadania, v. 19, n. 64, p. 113-126, 2014.

PAES DE PAULA, A. P. Abordagem Freudo-Frankfurtiana, pesquisaação e socioanálise: uma proposta alternativa para os Estudos Organizacionais. Cad. EBAPE.BR, v. 11, n. 4, p. 520-542, 2013.

PAES DE PAULA, A. P. Para além dos paradigmas nos estudos organizacionais: o círculo das matrizes epistemológicas. In: COLÓQUIO INTERNACIONAL DE EPISTEMOLOGIA E SOCIOLOGIA DA CIÊNCIA DA ADMINISTRAÇÃO, 4.; 2014, Florianópolis. Anais... Florianópolis: [s.n], 2014.

PAPADOPOULOS, Y.; WARIN, P. Are innovative, participatory and deliberative procedures in policy making democratic and effective? European Journal of Political Research, n. 46, p. 445-472, 2007.

PEDRO, A. P. Ética, moral, axiologia e valores: confusões e ambiguidades em torno de um conceito comum. Kriterion, v. 55, n. 130, p. $483-$ 498, 2014.

PEREIRA, J. R. Gestão social no contexto histórico e teórico das relações entre Estado, mercado e sociedade. In: COLÓQUIO INTERNACIONAL SOBRE PODER LOCAL, 12.; 2012, Salvador. Anais... Salvador: [s.n], 2012.

PERLATTO, F. Seletividade da esfera pública e esferas públicas subalternas: disputas e possibilidades na modernização brasileira. Revista de Sociologia e Política, v. 23, p. 121-145, 2015.

PIZZI, J. O mundo da vida: Husserl e Habermas. Ijuí, RS: Ed. Unijuí, 2006. PROCÓPIO, M. L. A dimensão moral das decisões administrativas e os limites da racionalidade limitada. In: COLÓQUIO INTERNACIONAL DE EPISTEMOLOGIA E SOCIOLOGIA DA CIÊNCIA DA ADMINISTRAÇÃO, 5.; 2015, Florianópolis. Anais... Florianópolis: [s.n], 2015.

PUTNAM, H. Reason, truth, and history. Cambridge, MA: Cambridge University Press, 1981.

PUTNAM, $\mathrm{H}$. The collapse of the fact/value dichotomy. Cambridge, MA: Harvard University Press, 2002.

PUTNAM, H. O colapso da verdade e outros ensaios. São Paulo: Ideias e Letras, 2008.

RODRIGUES, S. M. O Problema da validade de proposições morais no trabalho do professor. Revista Encontro de Pesquisa em Educação, v. 1, n. 1, p. 71-85, 2013.

RODRIGUES, S. M.; OLIVEIRA, J. R. As consequências para a educação da dicotomia entre fatos e valores morais. Revista Pesquisa em Foco, v. 6, n. 6 , p. 29-59, 2013.

ROUANET, S. P. As razões do lluminismo. São Paulo: Companhia das Letras, 1987.

ROUANET, S. P. Ética iluminista e ética discursiva. Revista Tempo Brasileiro, Rio de Janeiro, v. 98, p. 23-78, 1989.

ROWE, G.; FREWER, L. J. Public participation methods: a framework for evaluation. Science, Technology, \& Human Values, v. 25, n. 1, p. 3-29, 2000.

RYAN, K. E. Serving public interests in educational accountability: alternative approaches to democratic evaluation. American Journal of Evaluation, v. 25, n. 4, p. 443-460, 2004. 
Fatos, valores e o mundo-da-vida: argumentos epistemológicos para avaliação no âmbito da gestão social
Valderí de Castro Alcântara | Eloísa Helena de Souza Cabral Paulo de Tarso Muzy | José Roberto Pereira
SCHÜTZ, A. Fenomenologia e relações sociais. Rio de Janeiro: Zahar, 1979.

SEN, A. The possibility of social choice. The American Economic Review, v. 89, n. 3, p. 349-378, 1999.

SEN, A. Desenvolvimento como liberdade. São Paulo: Companhia das Letras, 2000.

SERVA, M. Abordagem substantiva e ação comunicativa: uma complementaridade proveitosa para a teoria das organizações. Revista de Administração Pública, v. 31, n. 2, p. 108-134, 1997.

SERVA, M.; ANDION, C. Por uma visão positiva da sociedade civil: uma análise histórica da sociedade civil organizada no Brasil. Cayapa: Revista Venezolana de Economía Social, v. 4, n. 7, p. 7-24, 2004.

SIEBENEICHLER, F. B. Introdução à edição brasileira. In: HABERMAS, J. Teoria do agir comunicativo: racionalidade da ação e racionalização social. São Paulo: Martins Fontes, 2012. VIII-XXVI p.

SIMON, H. A razão nas coisas humanas. Lisboa: Gradiva, 1989.

TENÓRIO, F. G. Gestão social: uma perspectiva conceitual. Rev. Adm. Pública, v. 32, n. 5, p. 7-23, 1998.

TENÓRIO, F. G. (Org.). Avaliação de projetos comunitários: uma abordagem prática. 4. ed. São Paulo: Loyola, 2003.

TENÓRIO, F. G. (Re)visitando o conceito de gestão social. Desenvolvimento em Questão, v. 3, p. 101-124, 2005.

TENÓRIO, F. G. Tem razão a gestão social? In: COLÓQUIO INTERNACIONAL DE EPISTEMOLOGIA E SOCIOLOGIA DA CIÊNCIA DA ADMINISTRAÇÃO, 3.; 2013, Florianópolis. Anais... Florianópolis: Universidade Federal de Santa Catarina, 2013. p. 1-17.
TENÓRIO, F. G.; KRONEMBERGER, T. S.; LAVINAS, L. V. Gestão social, extensão e Teologia da Libertação: uma análise a partir de um projeto junto a comunidades. Revista de Ciências da Administração, v. 16, n. 39, p. 224-235, 2014

TENÓRIO, F. G. et al. Critérios para a avaliação de processos decisórios participativos deliberativos na implementação de políticas públicas. In: ENCONTRO DE ADMINISTRAÇÃO PÚBLICA E GOVERNANÇA, 2008 Salvador. Anais... Curitiba: Anpad, 2008.

TENÓRIO, F. G. et al. Da redução sociológica à aplicação de critérios para a avaliação de processos decisórios participativos deliberativos em arranjos institucionais na esfera pública. In: ENCONTRO DE ESTUDOS ORGANIZACIONAIS. Anais... Florianópolis: Anpad, 2010.

VANDENBERGHE, F. The books that Habermas hasn't written. International Sociology, v. 26, p. 597-603, 2011.

VANDENBERGHE, F. Gestão social: uma disciplina em busca de teoria. In: ENCONTRO NACIONAL DE PESQUISADORES EM GESTÃO SOCIAL, 8.; 2014, Cachoeira. Anais... Cachoeira, BA: Universidade Federal do Recôncavo da Bahia, 2014.

VIZEU, F. Ação comunicativa e estudos organizacionais. Revista de Administração de Empresas, v. 45, n. 4, p. 10-21, 2005.

WALSH, V. Sen after Putnam. Review of Political Economy, v. 15, n. 3, p. 315-394, 2003.

WORTHEN, B. R.; SANDERS, J. R.; FITZPATRICK, J. L. Avaliação de programas: concepções práticas. São Paulo: Edusp, 2004.

Valderí de Castro Alcântara

Doutorando em Administração pela Universidade Federal de Lavras (UFLA); Mestre em Administração pela UFLA. E-mail: valderidecastroalcantara@gmail.com

Eloísa Helena de Souza Cabral

Doutora em Ciências Sociais pela Pontifícia Universidade Católica de São Paulo (PUC-SP); Professora Adjunta da Universidade Federal de Lavras (UFLA) / Departamento de Administração e Economia.E-mail: elocabral@uol.com.br

Paulo de Tarso Muzy

Doutor em Física Teórica pelo Instituto de Física da Universidade de São Paulo (USP); Reitoria da USP, Universidade de São Paulo E-mail: ptmuzy@uol.com.br

José Roberto Pereira

Doutor em Sociologia pela Universidade de Brasília (UNB); Professor Titular da Universidade Federal de Lavras (UFLA) / Departamento de Administração e Economia. E-mail: jrobertopereira2013@gmail.com 